\title{
Artelogie
}

Recherche sur les arts, le patrimoine et la littérature de l'Amérique latine

2 | 2012

Mexique : espace urbain et résistances artistiques et littéraires face à la « ville générique »

\section{Diego Rivera : technologie et mythologie}

\section{Edgard Vidal et Colette Grandclaudon}

\section{OpenEdition}

\section{Journals}

Édition électronique

URL : https://journals.openedition.org/artelogie/7823

DOI : 10.4000/artelogie.7823

ISSN : 2115-6395

Éditeur

Association ESCAL

Référence électronique

Edgard Vidal et Colette Grandclaudon, « Diego Rivera : technologie et mythologie », Artelogie [En ligne], 2 | 2012, mis en ligne le 21 janvier 2012, consulté le 07 janvier 2022. URL : http://

journals.openedition.org/artelogie/7823; DOI : https://doi.org/10.4000/artelogie.7823

Ce document a été généré automatiquement le 7 janvier 2022

Association ESCAL 


\title{
Diego Rivera : technologie et mythologie
}

\author{
Edgard Vidal et Colette Grandclaudon
}

\section{Partie I}

\section{« Le Mexique d'aujourd'hui et demain »}

1 Diego Rivera fait partie d'une génération d'artistes fondateurs de l'art muraliste mexicain ${ }^{1}$, sollicitée dans une période où le gouvernement, en recherche d'une identité face à l'Europe et aux Etats-Unis, fait appel aux artistes ${ }^{2}$. Les fresques peintes par Diego Rivera $^{3}$ au Palacio Nacional de Mexico représentent un des plus importants compendiums historiques effectués au XXe siècle. L'histoire du Mexique et de la ville de Mexico se lit dans un ensemble de sept peintures murales, partant de l'époque précolombienne jusqu'au vingtième siècle, en passant par les gestes fondateurs, les révoltes et les révolutions les plus signifiantes de ce pays. L'élaboration de cette œuvre majeure exigea cinq années, de 1929 à 1935 entrecoupées de commandes parallèles.

Ce média ne peut être affiché ici. Veuillez vous reporter à l'édition en ligne http:// journals.openedition.org/artelogie/7823

Parmi les peintures murales du Palais national, une fresque a davantage retenu notre attention: "Le Mexique d'aujourd'hui et de demain». Celle-ci s'inscrit dans le cycle "Epopée du peuple mexicain» et se situe à l'opposé de la fresque «Le Mexique préhispanique - le monde indien antique ».

4 Si la perspective est historique pour l'ensemble, elle est sans doute ici sociologique et sociale. Celle-ci n'exprime-t-elle pas les conflits et les tensions d'une société ? Ne se situe-t-elle sur fonds de grands événements: d'une part le Mexique a opéré sa révolution en 1910, suivie d'une guerre civile et de troubles jusqu'à la fin des années 1920 et d'autre part, il vient de connaître les répercussions de la grande crise boursière de 1929. Enfin, c'est à partir de cette période des années 30 qu'une politique de 
modernisation va naître à Mexico, à travers un urbanisme fonctionnel et l'industrialisation ${ }^{4}$.

Figure 1 - «Le Mexique d'aujourd'hui et demain » panneau gauche de l'ensemble peint au Palacio Nacional, Diego Rivera, 1935

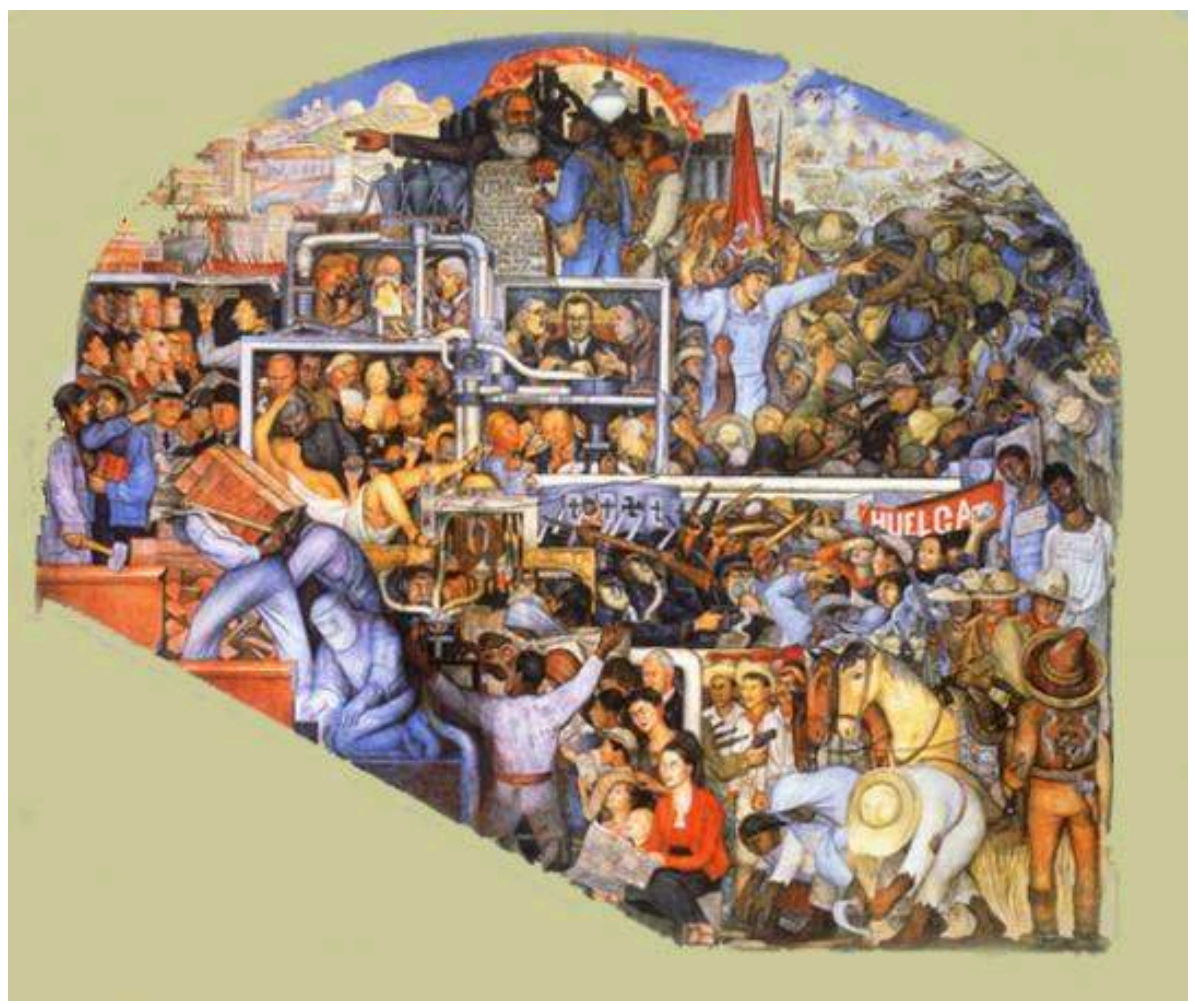

5 Face à une telle œuvre, d'abord on ne voit «rien»; toutefois ici, le « rien n'est (manifestement) pas rien $»^{5}$ : c'est la foule, massive, tumultueuse ; le sujet n'est-il le peuple, d'où émerge l'idée de travail, de révoltes, de violences de répression. Ici, pas de colonnes grecques ou antiques ${ }^{6}$, mais des tuyaux d'échafaudage de l'ère moderne, compartimentant ce qui paraît un vaste pêle-mêle. Les yeux sont attirés par les couleurs, des personnages géants, quelques visages reconnus. On repère des types (Indien, paysan, ouvrier ou bourgeois), on comprend des attitudes (oppositions, prières), on situe des zones turbulentes et d'autres stables; des sujets très précis, figurés; d'autres masses confuses. Dans la partie supérieure, émergent des villes, l'une en embrasement, l'autre ensoleillée mais étrangement vide. L'ensemble est parsemé d'écrits; la banderole " grève » retient l'attention tout comme « la constitution » à la manière de la Table de la Loi de Moïse, sur fond d'usines très sombres.

\section{Méthodologie}

De loin, parmi le fouillis de masses tumultueuses, le regard s'accroche à l'échafaudage blanc. Au sein d'un compartiment stable, trône un objet plus mystérieux au sein d'une réunion de personnages. L'identité de ce détail ne peut être cernée sans un regard de près. Cependant, une observation méditative de cet objet mystérieux et central nous invitera à " voir se lever » le tableau (selon la magnifique expression de Arasse) ${ }^{7}$ et d'établir l'articulation de l'artefact avec l'échafaudage des tuyaux et la grande œuvre de Diego. 
7 «Dieu niche dans les détails» nous avertit Aby Warburg8. Daniel Arasse a ouvert un nouveau champ de l'histoire de la peinture en abordant le statut du détail, mettant en cause les catégories de l'histoire de l'art, qui lui semblaient avoir été établies trop « de loin»: Il tente d'élaborer une typologie des détails dans une histoire "qui échappe toujours $»^{9}$. Pour Arasse, le détail recouvre des éléments discrets et d'ordres différents. Détail iconique, lié au message du tableau; détail pictural, taches qui condensent le système du tableau, mais le défont en même temps. Dans l'histoire iconographique, le détail peut être «normal » ou " un danger » ou « une erreur »; être vu dans la vérité de son aspect, son imitation ou ses idéaux ; il peut faire événement, écart ou anomalie, ou encore «choqué », "faire émeute $»^{10}$ et le rôle de l'historien est "de l'éteindre et le lisser » en l'expliquant. A travers le temps, le statut du détail a évolué. Daniel Arasse étudie celui-ci sur six siècles de peinture, de l'intervention de la perspective à la fin de la figuration, tout en restant prudent sur l'art contemporain ${ }^{11}$. Il soulève de multiples questions.

8 Le peintre mexicain, dans cette fresque, présente la particularité d'être «à cheval » sur divers systèmes de représentation. Il affirme la figuration réaliste, mais ne renie pas l'importance de l'apport du Cubisme. Ainsi, Anna Indych-Lopez ${ }^{12}$ analyse-t-elle "le Cubisme de l'échafaudage ": "Rivera reinforces the structural sense of Cubist scaffolding by contracting (..); "Rivera strategically exploits the possibilities of the Cubist scafflod to undermine viewers expectations - narrative, pictorial and stylistic." ${ }^{13}$. Ce qui rend l'approche plus complexe.

9 Le détail que nous abordons présente aussi la particularité d'être à la fois « bien placé et visible » mais manifestement, dans la longue réception de la critique d'art, de Silva à Colonel Rivera, «transparent » « invisible » « un non événement ». C'est ce caractère de non événement, cet écart ou la résistance de la réception qui nous a frappés. Ce, d'autant plus que les personnages qui l'entourent focalisent l'attention, provoquant nombre de commentaires et une magnificence de détails. Ce, parce que ceux qui l'entourent réunissent les membres de l'élite internationale et sont placés par le peintre dans une attitude d'extrême attention et même presque de vénération de l'objet. Ainsi avons-nous affaire à une sorte de paradoxe de non événement de cet objet.

10 A notre tour, nous avons posé un regard, intrigué, sur l'objet enveloppé d'un aura, nous obligeant à le voir et à repérer les sinuosités de sa production de bandes et les ramifications de ses connexions, qui, d'abord petites, prennent du volume et gagnent un réseau tubulaire : sa complexité nous introduit dans un labyrinthe de ramifications : nous avons dès lors affaire à des jeux de mouvements et de cadres autour de l'artefact.

11 Ainsi le fragment délimité, avec l'objet et ses articulations à différentes scènes de vie, retentit avec la totalité de l'œuvre en "échos silencieux dans toute sa profondeur et dans toute son étendue $»^{14}$. Pour saisir ce retentissement, analyser cette " présence discrète ou invisible ", quelle méthodologie utiliser ? Divers moyens ont été réunis : d'abord un travail sur le processus de réception de l'œuvre, traduisant que l'objet n'est pas objet en soi-même, mais la suite d'une longue chaine d'interprétations. Ensuite un travail sur le processus de création, prenant en compte le contexte socio-historique situant la place de l'artiste et son œuvre, avec recours au parcours biographique du peintre, aux lettres, déclarations et croquis préparatoires à l'œuvre. Ces outils ont été utiles à la compréhension des hésitations, des doutes, des retours en arrière, de tous ces moments de tremblement de la création. Nous avons aussi effectué des comparaisons avec d'autres œuvres importantes, picturales et littéraires, d'époques différentes. Et enfin, 
naturellement, mais il est nécessaire de le souligner, nous avons procédé à « un regard de près et de loin » du détail, nous avons posé un regard méticuleux, interrogatif voire méditatif sur l'œuvre.

12 Ce long mouvement ne traduit-il l'idée que l'interprétation est un jeu de dévoilement continu et un éternel triomphe sur la doxa ou encore, que l'œuvre n'est jamais qu'un entrelacement dynamique de saisissement, de dessaisissement et de ressaisissement? Comme l'affirme Faure, en négligeant peut-être l'aspect important de la réception « ... quelle que soit la forme sous laquelle il nous est offert, qu'il soit actuellement vrai ou vrai dans notre désir, qu'il soit vrai à la fois dans son apparence immédiate et dans ses destinées possibles, l'objet par lui-même, le fait par lui-même ne sont rien. Ils ne valent que par leurs relations infiniment nombreuses avec une ambiance infiniment complexe et jamais semblable à une autre, qui traduisent des sentiments universels d'une infinie simplicité. $»^{15}$

\section{De la création à la réception du fragment. Un curieux artefact}

Figure 2 - Fragment de la peinture murale gauche « Mexique d'aujourd'hui à demain » au Palacio Nacional à Mexico. Diego Rivera, 1935

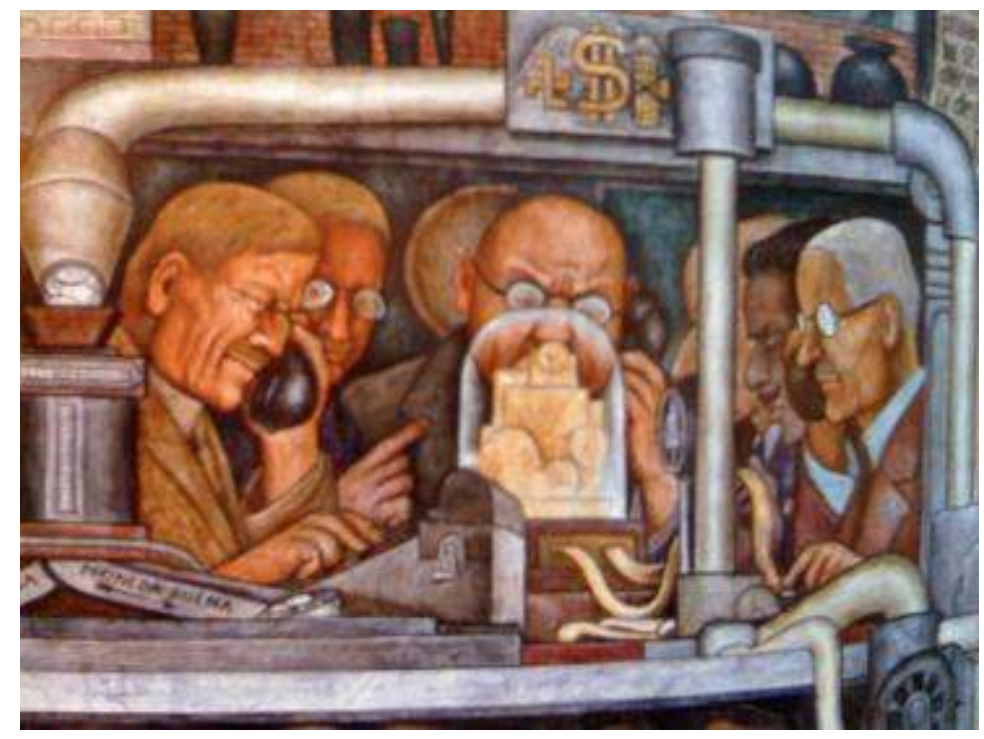

L'étrange artefact rayonne au centre de la réunion, telle une sorte de boule de cristal ou une horloge avec deux longues bandes de papier. À côté de deux téléphones et d'une machine calculatrice, cette image-là offre de la part de Diego Rivera la plus précise reproduction d'un téléscripteur des années 1930. Ancêtre de l'ordinateur, chaînon manquant entre le télégraphe et le télétype, il fait partie des moyens technologiques dont dispose l'activité financière pour se développer entre les années 1870 à 1940 . Le spécimen peint par Rivera est un modèle type Burry Stock Ticker qui a remplacé le premier modèle inventé par Edison.Il a été initialement inventé par M.A. Wirshing et amélioré par M. John Burry. En 1910, la Western Union disposait de milliers de tickers Burry ${ }^{16}$. 
Figure 3 - Image du télescripteur inventé par M.A. Wirshing et amélioré par M. John Burry

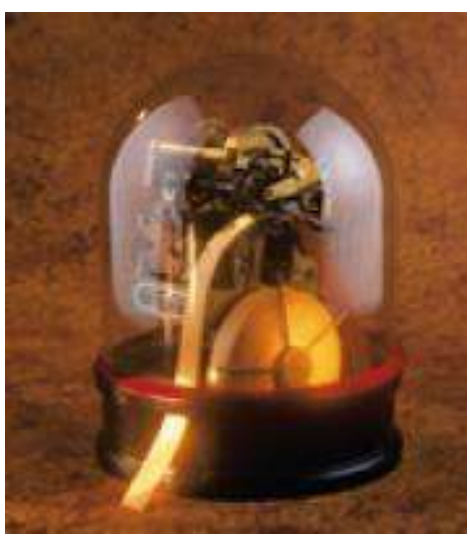

Photo : Stock Ticker Company 1

La photographie du téléscripteur présente l'appareil sous une coupole de verre; à l'intérieur, un moteur agglomère un fouillis de pièces métalliques; à sa base, émerge une grosse roue avec trois rayons autour de l'axe. Le rouleau de papier passe sous des turbines et sort de la cage de verre en méandres imprimés. En dehors du papier et de cette roue, de couleur claire, les éléments de la machine, son moteur en forme de dôme et son socle, sont de couleur sombre.

15 La peinture réalisée dans la fresque est-elle fidèle à la réalité ? Quelques différences sont à noter avec la photographie. Le globe de verre recouvre un édifice pyramidal. La composition emboite un petit dôme, des structures carrées et rondes, reposant sur un socle à deux marches d'où émergent deux bandes de papier. Sauf la base, l'édifice entier est de couleur or et le globe protecteur l'irise d'une aura. Les bandes de papier qu'il émet serpentent derrière la colonne centrale, se prolongent et rejoignent d'autres tuyaux. Par de petits tuyaux à sa base, l'appareil est raccordé à d'autres tuyaux que le regard est appelé à suivre. Ainsi découvre-t-on que ces tuyaux encadrent et tapissent le compartiment. A gauche, le gros tuyau crache de l'argent qui coule dans d'autres tuyaux prenant des directions différentes. Ils sortent du cadre. On se perd alors dans un labyrinthe de méandres des tuyaux, de taille différente, avec des embranchements, des coudes, des nœuds. On est perdu au milieu d'une espèce de monstre hybride, on reste aux prises avec ces tentacules qui apparaissent, disparaissent et réémergent ailleurs.

Dans le compartiment, la réunion est étrangement traversée par un cylindre décalé sur la droite, créant une séparation entre les deux hommes avec leur téléphone. L'un semble en conversation et montre de son doigt l'appareil ; l'autre, à l'écoute attentive, pose un doigt sur la banderole de papier. Nous reviendrons sur cette colonne qui forme une croix avec, au sommet, une inscription.

\section{« Le Festin de Wall Street »}

Ce fragment que nous avons remarqué se retrouve dans une peinture murale antérieure, avec le même ensemble significatif d'hommes riches et du téléscripteur. En 1928 et pour la première fois, Rivera dessine un téléscripteur dans le mur nord du Patio de las Fiestas de la Secretaria de Educacion Publica, dans le fameux panneau intitulé Le Festin de Wall Street. L'appareil trône cette fois-ci devant un coffre, sur la table avec le 
champagne dans son saut de glace et une statue de la liberté - lampe et d'autres objets énigmatiques.

Figure 4 - «Le festin de Wall Street » à la Secretaria de Educación Pública, Mexico - Diego Rivera, 1928

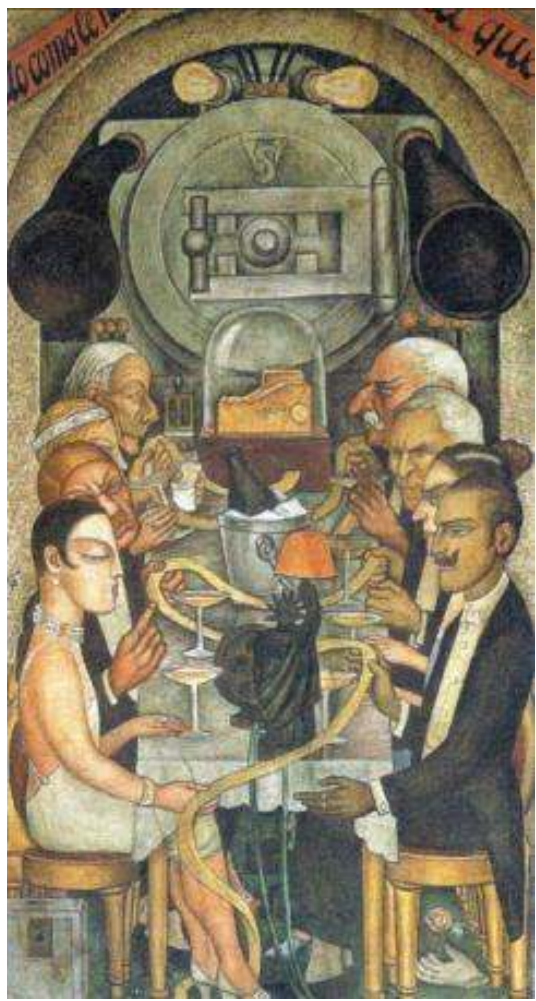

Si l'appareil précédent était relié à différentes sortes de tuyaux, l'image présente montre de façon magistrale la production d'un véritable serpent de papier circulant entre les membres de l'élite financière, leurs épouses et leurs verres de champagne. Ils manifestent une concentration sur la précieuse banderole. Reliés à un appareil rond sur la table, deux fils noirs glissent à terre. Signalons sous le siège de la femme à gauche, un objet métallique ressemblant à un coffre et sous le siège à droite, une étrange main coupée tenant une rose ${ }^{17}$.

Le téléscripteur présente encore bien des différences avec la photographie. Il ressemble à une montagne ou à un sarcophage avec un œil égyptien et un rond en relief. Dans ce compartiment, une multiplicité de cercles s'offre à la vue : ronds de la porte, des serrures et des gonds du coffre-fort, ronds des bouches des hauts parleurs, ampoules et lampe rondes, saut à champagne rond, énigmatique machine ronde reliée aux deux fils sombres, chaises à l'assise et au dossier ronds, bagues, colliers et serre-cheveux en couronne, mèche de cheveux en accroche-cœur, arrondis des bords de la nappe... La scène s'inscrit dans l'architecture d'une abside en parfaite symétrie avec l'enveloppe de verre du téléscripteur, renforçant l'idée de son importance cruciale et de lieu « saint». Cet ensemble pourrait préfigurer par son antécédent isomorphisme le fragment de la fresque de 1929-1935, que nous étudions. Il est impossible de ne pas voir le téléscripteur et le bouton de l'énorme coffre-fort, ils se situent dans une perspective où l'œil se centre, dans le cadre de la mise en scène. Et cependant, dans la longue histoire de la réception de ces fresques de Rivera, il est passé inaperçu. 


\section{« L'objet invisible » : analyse de la réception}

Nous avons recherché des commentaires à partir de deux types d'ouvrages différents. D'une part les ouvrages d'art, très appliqués dans leurs analyses iconographiques; d'autre part, les ouvrages et guides touristiques édités par le Palacio National ou par des organismes officiels de l'Etat mexicain, et présentant aussi des descriptions fines. L'analyse globale de ces ouvrages a permis de recueillir des informations précieuses sur la qualité et les fonctions des grands personnages qui se trouvent dans le compartiment où trône le téléscripteur et de cerner la réception de l'œuvre de Diego Rivera.

Quatre guides touristiques ont été retenus. Ils nous livrent chacun leurs observations. Silva ${ }^{18}$ est l'un des premiers critiques de l'œuvre du peintre. Il dit que «pendant que John Rockefeller parle au téléphone, Harry Sinclair pointe son index droit vers une coupole en verre (glass-dome)». En 1966, le teleprinter GB, ou teletypewriter US était presque hors d'usage. Ainsi, l'ouvrage «Diego Rivera: sus frescos en el Palacio Nacional de México, breve descripcion de los detalles, Volume $1 »^{19}$ situe les personnages Andrew Mellon, Vanderbilt, JP Morgan, William Durant, Sinclair et Rockefeller, ils «enregistrent les cotations boursières dans une machine ». Le guide « Guía de murales del Centro Histórico de la Ciudad de México $\rrbracket^{20}(1984)$ mentionne d'emblée que cette scène de la fresque a été réalisée suite à la polémique Rockefeller avec Rivera au sujet du panneau mural qui lui avait été commandé par le Rockefeller Center de New York.

Le guide touristique "La ciudad de México: centro histórico» (1997) ${ }^{21}$ caractérise Rockefeller comme «le créateur d'une dynastie bancaire américaine ». Il indique ensuite les noms des personnages autour de la table : Harry Sinclair, William Durant, JP Morgan, Cornelius Vanderbilt et Andrew Mellon.

23 Aucun de ces ouvrages ne parle du téléscripteur. Ce n'est que dans l'ancien guide touristique du Palacio Nacional publié en 1961 que nous trouvons une mention de l'objet "qui trône au centre de la réunion des riches de la planète ». A propos de la «Diego Rivera's frescoes in the National Palace of Mexico City", il est précisé que des gens très connus regardent la bandelette du téléscripteur (ticker tape) avec des informations sur le marché boursier de New York. De droite à gauche, ce sont: "Andrew Mellon, l'extrésorier des Etats-Unis; Cornelius Vanderbilt, un financier, philanthrope et éminent homme d'affaire des chemins de fer; JP Morgan, dont le nez est la seule chose qui peut être vue derrière le tuyau de l'argent; William Durant au centre, l'ancien chef de la General Motors des Etats-Unis ; Harry Sinclair ; Rockefeller Jr. est quant à lui à leur droite dans le compartiment $\gg .{ }^{22}$

24 Notre analyse s'est poursuivie sur les catalogues ou ouvrages d'art. La dernière et monumentale édition de Taschen "The Complete Murals» de J.M. Lozano et Coronel Rivera $^{23}$ (2009) présente l'avantage de nombreux croquis et de magnifiques illustrations. Ainsi ce croquis de la fresque gauche du Palacio National donne-t-il des points de repère très utiles. 


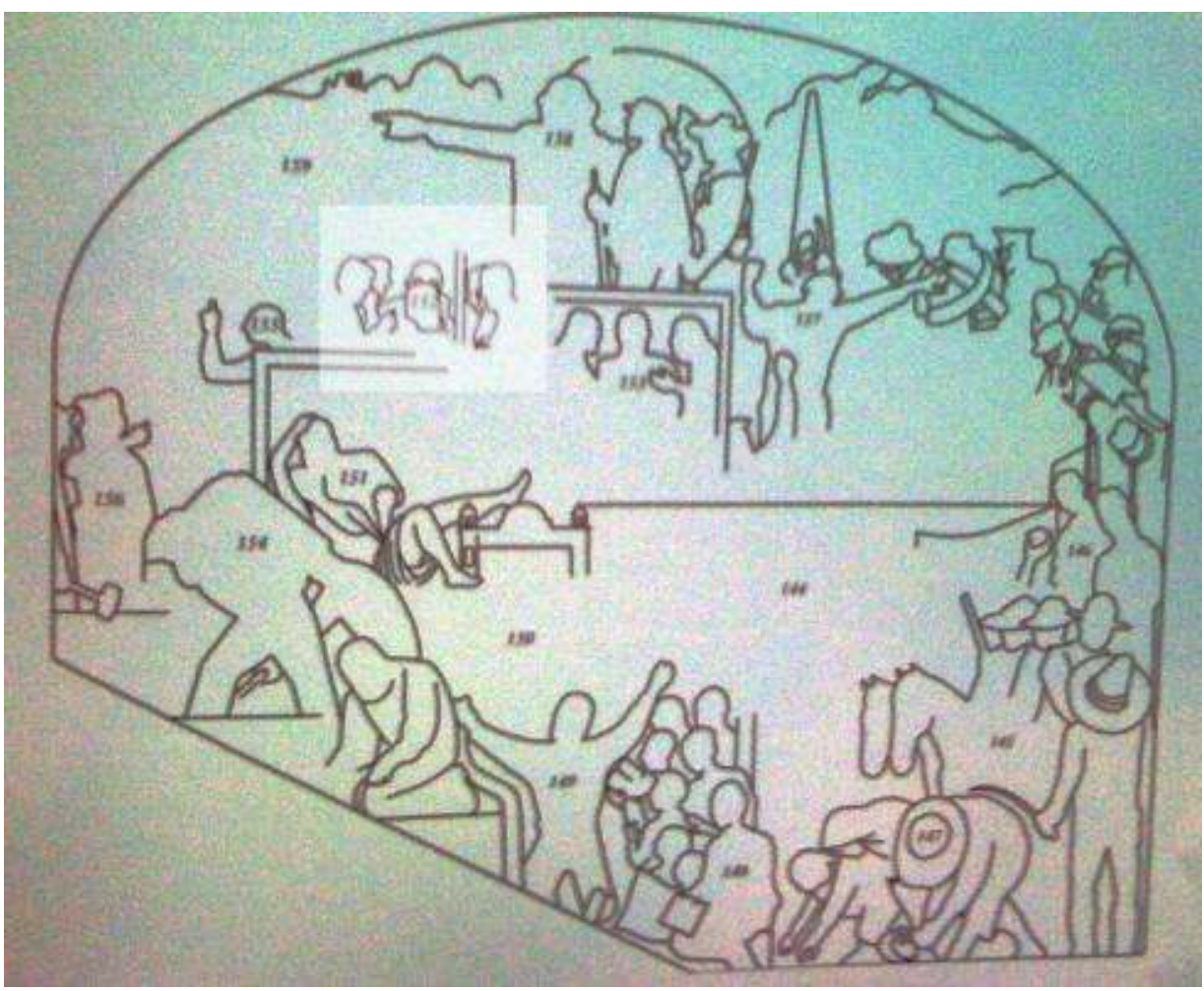

Le numéro 152 correspond au téléscripteur. Cependant la notice décrivant la scène traite de la bourgeoisie des Etats-Unis, de gauche à droite : Rockefeller, Sinclair, Durant, Morgan, Vanderbilt et Mellon. Aucune mention à l'objet sur lequel est déposé le numéro 152.

Dans son "Diego Rivera: catálogo general de obra mural y fotografía personal (Mexico, 1988) $»^{24}$, Laura Cortés Gutiérrez, de l'Instituto Nacional de Bellas Artes, cite aussi : «John O. Rockefeller Ir. ; Harry Sinclair ; William Durant, ancien directeur de la General Motors; JP Morgan; Cornelius Vanderbilt, financier des chemins de fer nord américains et philanthrope et Andrew Mellon, ex-trésorier des Etats-Unis ».

Dans «Rivera, les fresques de Mexico ${ }^{25}$, Mordrel parle de "l'encadré (visible en partie seulement) qui montre le secrétaire d'Etat américain Mellon, les milliardaires Vanderbilt, Morgan, Rockefeller et Sinclair suivant le cours de la bourse». Le texte "The Mexican muralists in the United States ${ }^{26}$ rassemble des travaux sur Jose Clemente Orozco, Diego Rivera, et David Alfaro Siqueiros, et une discussion sur l'impact de ces muralistes sur les peintres américains. Lorsqu'il analyse le fragment que nous étudions, il détaille les « North American capitalists » et il cite dans l'ordre : «Mellon, Vanderbilt, Morgan, Sinclair, Rockefeller ». Dans son important article, Llana Lowy énumère aussi de gauche à droite «les milliardaires John D. Rockefeller, Jr., Harry Sinclair, William Durant, J. P. Morgan et Cornelius Vanderbilt, et aussi un représentant du pouvoir politique américain Andrew Mellow, ministre des Finances des U.S.A. $"^{27}$. Dans le prologue d'une anthologie de la poésie nordaméricaine éditée par le Ministère de Culture de Venezuela en 2007 et publié en 2008 par la revue de Casa de América ${ }^{28}$, Ernesto Cardenal affirme que Rivera dans sa fameuse composition murale "satirise les "Constructeurs de l'Empire » Rockefeller, Vanderbilt, Morgan, Mellon, qui avaient "exploité l'Amérique jusqu'à la laisser sèche et décharnée ». 

connu une meilleure fortune. Toutefois, sur 11 ouvrages recensés, entre les années soixante jusqu'en 2000, à peine la moitié parlent de l'appareil qui est pourtant au centre de la table. Ni Jacqueline Barnitz ( 2001) qui cite "JD Rockefeller, Henry Ford, and JP Morgan parmi les convives ${ }^{29}$, dans le Banquet de Wall Street Rivera, ni David Craven dans «Diego Rivera : as epic modernist » ${ }^{30}$ (1997) qui liste avec ironie les trois magnats des finances dans le «Wall Street Banquet », ni Desmond Rochfort dans « The murals of Diego Rivera ${ }^{31}$ (1998) qui nomme seulement deux personnages, Morgan et Ford, ni Masha Zakheim dans son livre sur Diego Rivera en San Francisco ${ }^{32}$ (1998), ni Enrique Krauze ${ }^{33}$ dans son travail publié en 2002 ne mentionnent le téléscripteur. Venons-en à ceux qui parlent du téléscripteur, aux cinq exceptions. Bertram David Wolfe, le meilleur biographe et ami de Rivera ${ }^{34}$, qui participe à plusieurs livres en collaboration avec le peintre, ne se limite pas à l'image montrant «les capitalistes mexicains et américains et leurs femmes ", mais décrit la table avec le téléscripteur et des coupes de champagne, le coffre de banque, des haut-parleurs, la longue bande du téléscripteur, et une réplique de la statue de la Liberté. En voyant les caricatures de John D. Rockefeller, de JP Morgan, et Henry Ford peints en 1928, il soutient que lorsque les Rockefeller embauchaient Diego pour décorer Radio City en 1933, ils ne pouvaient pas prétendre qu'ils n'étaient pas prévenus... Soulignons le travail de Laurence Eli Schmeckebier ${ }^{35}$ citant le «ticker-tape » et celui Patrick Marnham ${ }^{36}$, en 2000, dans son texte « Dreaming with his eyes open: a life of Diego Rivera ", affirme que Rivera " peint les millionnaires (John D. Rockefeller, Henry Ford and JP Morgan) penchés sur la bande du téléscripteur qui serpente ». Les citent également, dans la décennie 1990, James D. Cockcroft ${ }^{37}$ en 1991 et Carlos M. Jiménez en $1994^{38}$. Rappelons enfin Robert Lacey ${ }^{39}$ (1971) dans un texte non sur le peintre mais sur son personnage, Ford, avec pour titre suggestif « Ford: l'homme et la machine », édité en 1986.

\section{Les tuyaux blancs et leur enchevêtrement}

Et cependant, il nous a paru que cet objet était central et crucial. L'observation a aussi révélé à quel point cet artefact est connecté à un enchevêtrement de tubes. Nous allons à présent prendre du recul par rapport à ce réseau tubulaire, en l'observant de loin puis nous nous arrêterons sur un lieu d'émission de ces tuyaux au sein de l'Eglise. 
Figure 6 - Mise en valeur du réseau tubulaire de la fresque « Le Mexique d'aujourd'hui et demain » panneau gauche de l'ensemble peint au Palacio Nacional, Diego Rivera, 1935

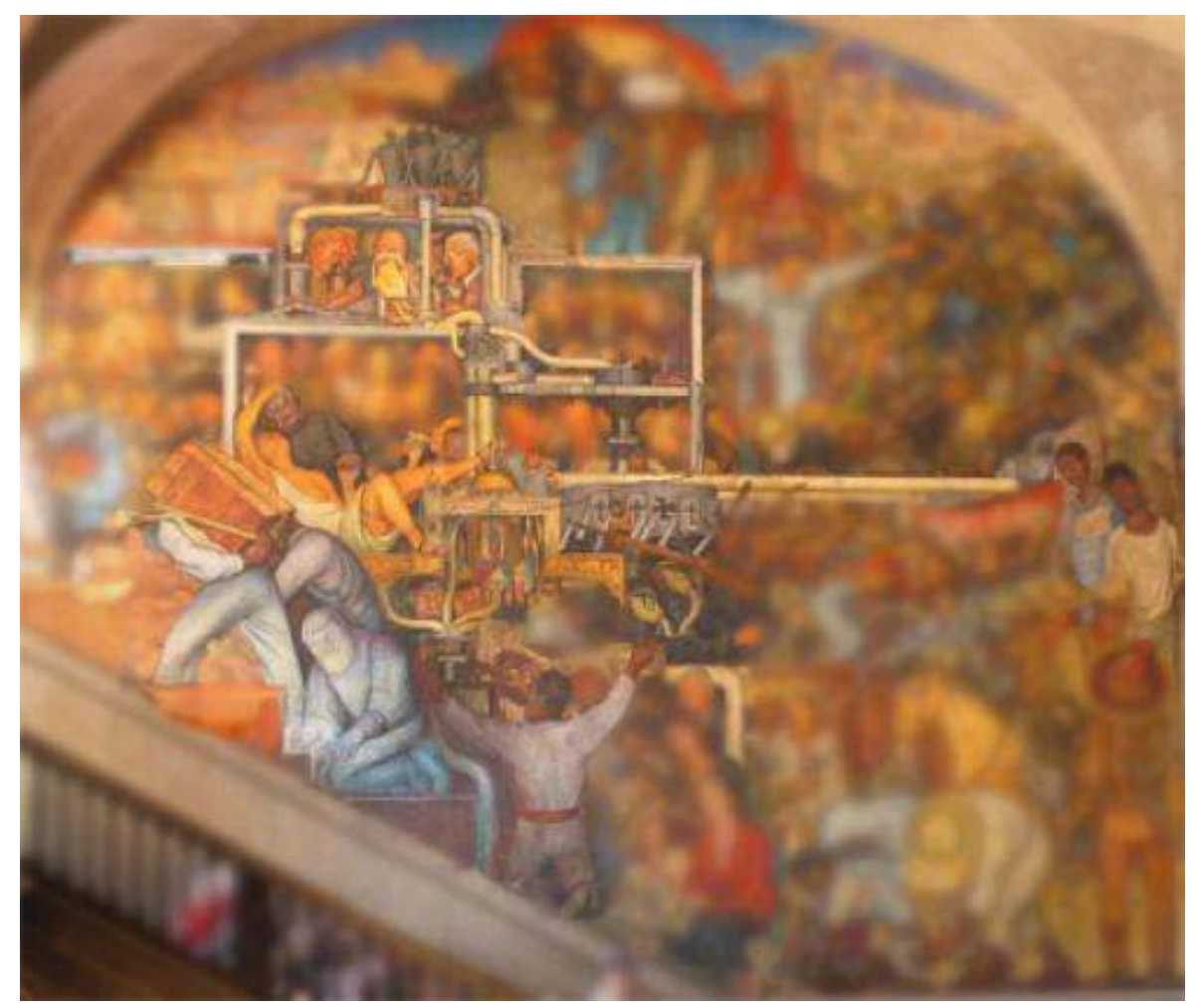

De loin, le regard fugitif suit les tuyaux blancs... jusqu'au soleil en flammes rouges. Echafaudage, tantôt souples tuyaux, reliant des machines, accompagnant la structure dure de murs d'architecture, tantôt sorte de légers rubans serpentant. Ils se donnent à voir pleinement ou surgissent brusquement et disparaissent. L'artiste leur a choisi la couleur blanche, d'un blanc éclatant. C'est aussi le blanc qu'utilise Diego pour présenter le serpent à plume, crachant le feu, de la culture Aztèque. Faut-il établir un parallèle entre les tuyaux d'échafaudage «qui serpente » dans cette fresque, et le serpent blanc aztèque dans la fresque qui lui fait pendant? Faut-il observer la mutation d'une forme en une autre, tout en en maintenant l'idée d'une énergie fabuleuse, structurante, essentielle, majeure, formidable? Ici, le serpent n'est plus, les tuyaux de la modernité l'ont remplacé. Passage de la tradition à la modernité, mais la modernité ne se nourritelle pas de la tradition, la tradition fortement ancrée n'innerverait-elle pas la structure des pensées et l'œuvre même présentée. Dans le croquis préparatoire à l'œuvre, à l'origine du processus de création de la fresque, Rivera prévoyait de placer le serpent à plumes Quetzalcóatl au centre. Dans ce croquis, le serpent enroulé autour de la montagne et s'apprêtant à se dérouler domine magistralement la scène. 
Figure 7 - Croquis préparatoire de la fresque «Le Mexique d'aujourd'hui et demain » panneau gauche de l'ensemble peint au Palacio Nacional, crayon sur papier

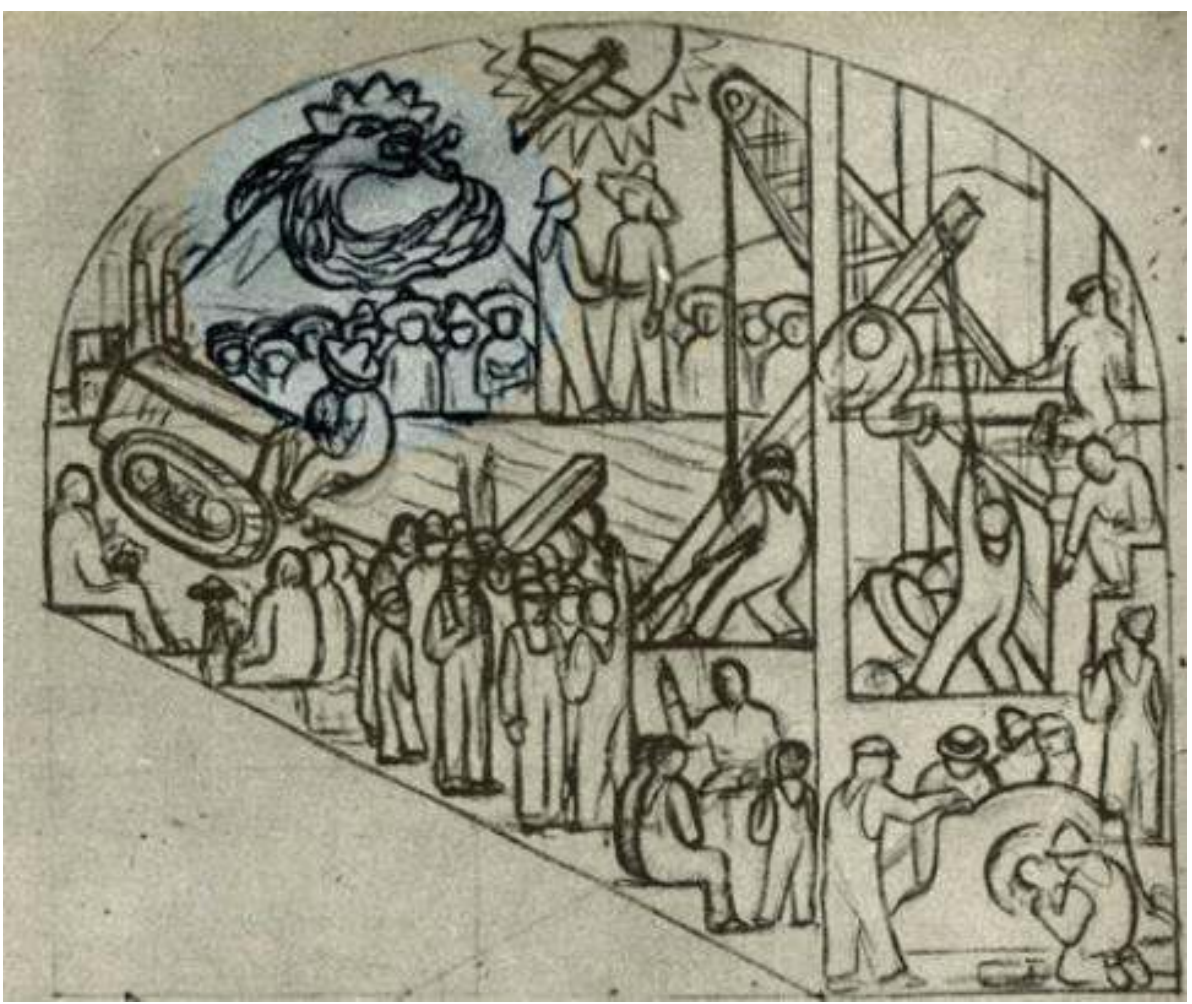

Coleccion Museo Tecnologico de la Comision Federal de Electricidad, Diego Rivera, 1925 (Sánchez Hernández, 2003 : 78)

32 Visiblement, cette structure tubulaire a de multiples fonctions. Lowy les précise ${ }^{40}:$ les tuyaux encadrent (les classes dominantes) conduisent (argent, papiers de la Bourse, ordres et informations), relient (les compartiments), séparent (les uns des autres, des classes populaires); instaurent une hiérarchie (à l'intérieur des pouvoirs): sa description est fidèle. A cette liste des fonctions de ce réseau tubulaire, nous en rajoutons une : ces tuyaux sont pareils à des flèches qui conduisent le regard à des scènes. 
Figure 8 - Embranchement des tuyaux, fragment de la fresque "Le Mexique d'aujourd'hui et demain » panneau gauche de l'ensemble peint au Palacio Nacional, Diego Rivera, 1935

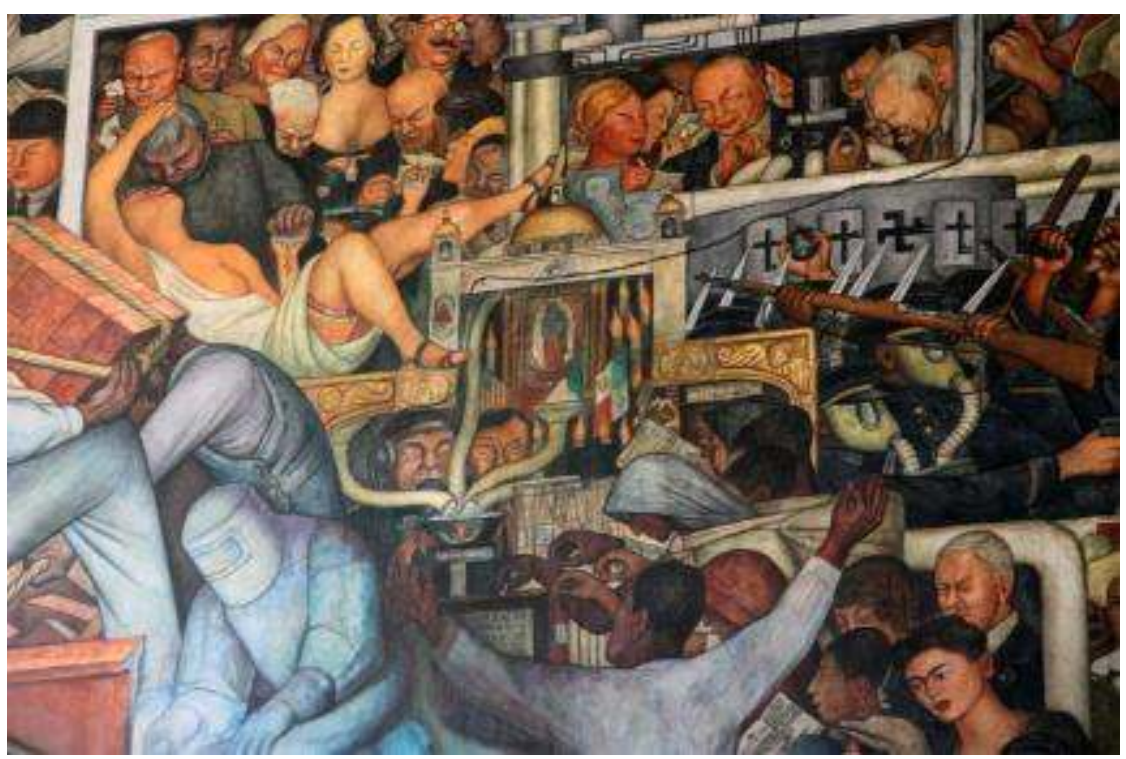

Le téléscripteur-tabernacle constitue le pendant inversé de l'icône de la vierge Guadalupe. Or l'intérieur de l'Eglise cristallise un point de rassemblement et de départ du réseau tubulaire, tout comme le téléscripteur le faisait avec ses bandes serpentant à la base de la colonne. Il faut observer de près l'embranchement de tuyaux issu du chapiteau au sommet d'une colonne de la nef, proche de l'icône de la vierge. La voute n'est pas portée par des arcs mais irriguée de ces tuyaux serpentant. Ils permettent la circulation de l'argent, qui apparaît, déversé ou aspiré, au lieu de leur convergence. Ils dirigent aussi le regard vers différentes scènes.

Première branche de tuyau : « le Serpent » vers l'icône de la Vierge de la Guadalupe. 
Figure 9 - Branche de tuyau vers la Vierge, fragment de la fresque "Le Mexique d'aujourd'hui et demain » panneau gauche de l'ensemble peint au Palacio Nacional, Diego Rivera, 1935

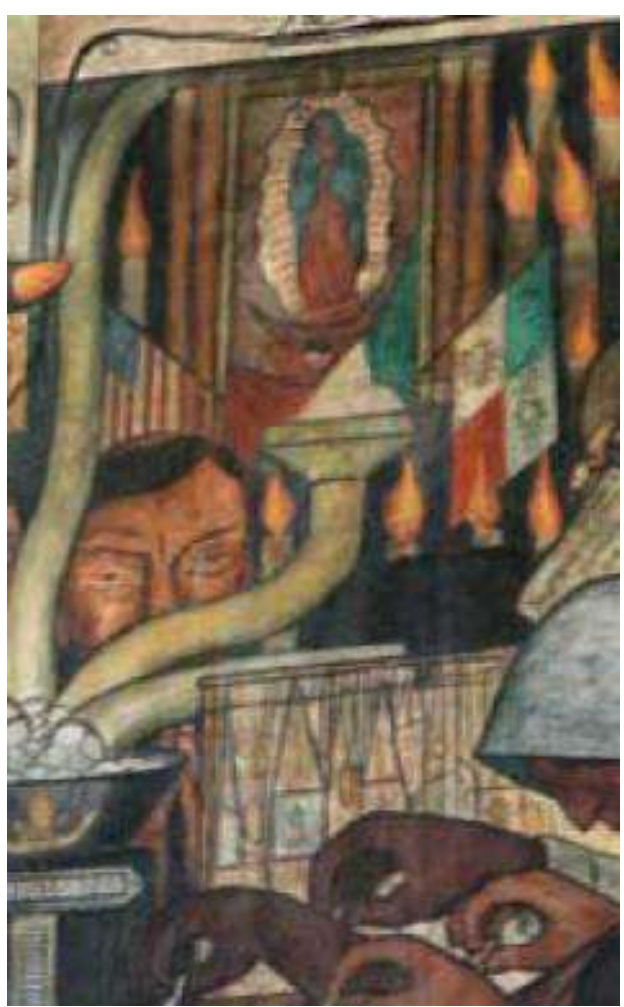

L'aboutissement du tuyau forme la pointe d'une flèche désignant la petite Vierge de la Guadalupe, dans son sanctuaire, enveloppée de 9 chandeliers et encadrée par les drapeaux américains et mexicains ${ }^{41}$. De la vasque ne s'élève ni une pointe, ni une flamme, ni un trésor d'argent: la flèche blanche correspond à la partie blanche du drapeau mexicain. Ce blanc du drapeau mexicain symbolise la religion catholique ${ }^{42}$ et la paix $^{43}$. Le tuyau évoque le serpent, traditionnellement représenté avec la Vierge et rappelant aussi l'origine de la Chute d'Adam et Eve, exilés du Paradis. Tourné vers la petite Vierge de Guadalupe, un Indien prie, éploré. Ses bras déployés s'inscrivent en correspondance avec le geste de l'ange sous les pieds de la Vierge. Des fidèles, des indiennes, formulent des prières, demandent des indulgences et versent leur obole dans le tronc ; habituellement situé contre un mur, il est ici situé contre la colonne.

Deuxième branche de tuyau : vers « la scène scandaleuse ». 
Figure 10 - Branche de tuyau vers la prostituée, fragment de la fresque «Le Mexique d'aujourd'hui et demain » panneau gauche de l'ensemble peint au Palacio Nacional, Diego Rivera, 1935

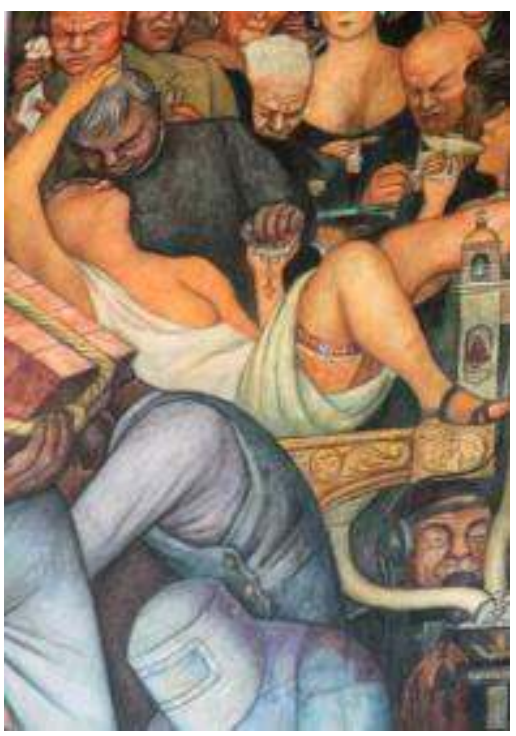

Le tuyau soutient le compartiment où se trouve réunie une société bourgeoise, pour une fête voire, apparemment, une orgie. Une prostituée de grande taille, déshabillée de sa robe blanche, est exposée, renversée, sur l'édifice de l'Eglise comme sur un trône ; elle est enlacée par un prêtre qui s'apprête à un baiser sur sa bouche. Un billet est glissé entre leurs mains qui se rejoignent. Sur l'avant-bras de la prostituée, pend un chapelet avec une croix inversée, qui forme une opposition avec la croix de l'Eglise. Tout près d'elle une femme tend une coupe de champagne. Nul doute que cette représentation osée et audacieuse provoqua un scandale. Cependant, ce lieu ne reflète guère une fête, car personne ne rit ni ne sourit. A côté de la belle femme et du prêtre, les hommes ferment les yeux, baissent les yeux, regardent de côté, regardent d'un seul œil, ont le nez dans leur verre. C'est plutôt l'idée d'embarras qui domine. Cette scène et la taille monumentale que donne Diego à la prostituée ne renvoie-t-elle pas à 'la Grande Prostituée de Babylone', de l'Apocalypse de Saint-Jean ? Nous reviendrons sur ce point. Elle s'inscrit elle aussi en contrepoint de la vierge de la Guadalupe et du moine en bure dans le compartiment supérieur.

Le tuyau central : vers le téléscripteur. 
Figure 11 - Branche vers le téléscripteur, fragment de la fresque «Le Mexique d'aujourd'hui et demain » panneau gauche de l'ensemble peint au Palacio Nacional, Diego Rivera, 1935

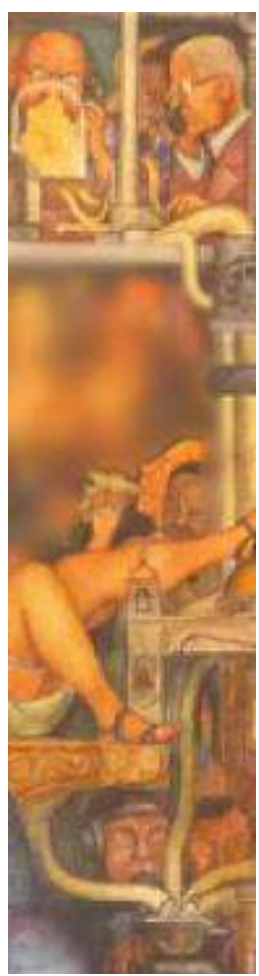

Le tuyau central se prolonge à la verticale, il s'élève, se noue à d'autres tuyaux et rejoint exactement le téléscripteur; il rejoint également la colonne traversant le compartiment de la haute finance, et débouche sur les symboles de la croix, du dollar et du faisceau fasciste ${ }^{44}$.

Le très discret tuyau sur la droite du chapiteau: vers la caserne et les forces répressives?

Figure 12 - Branche sur les forces répressives, fragment de la fresque « Le Mexique d'aujourd'hui et demain " panneau gauche de l'ensemble peint au Palacio Nacional, Diego Rivera, 1935

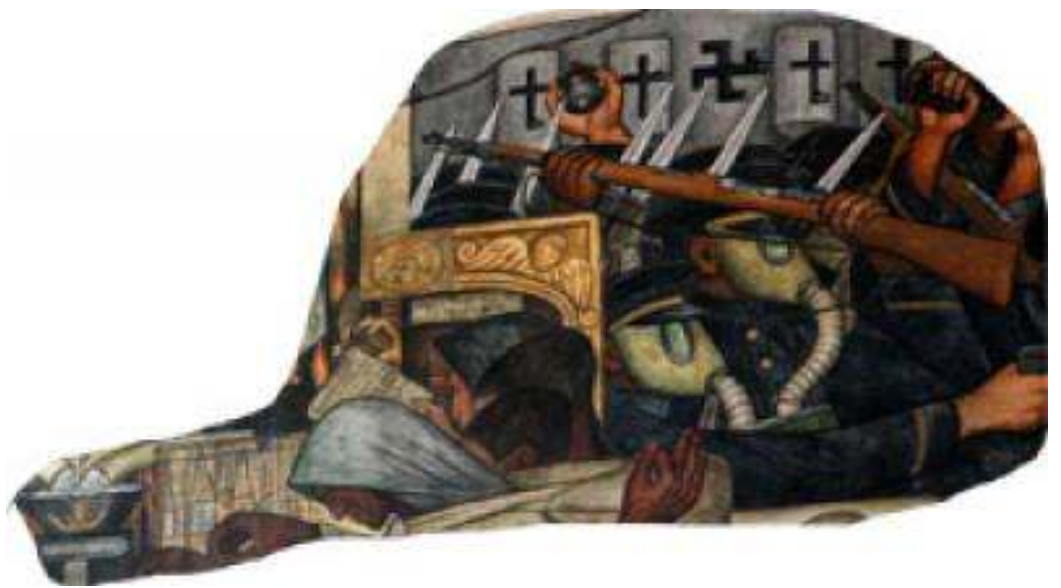

41 Issu du chapiteau de l'Eglise, un tuyau très discret passe sous les drapeaux mexicains et s'enfonce dans une sorte de vague noire, similaire à la houle noire des forces répressives, et vers la caserne. La bataille fait rage. Sur le seuil de l'Eglise, un insurgé s'apprête à lancer une pierre ; parmi les forces répressives, une main dressée s'apprête 
à jeter une bombe de gaz toxique sur les rebelles; des têtes masquées semblables à des têtes d'hydres jaillissent. Nous en avons compté sept; en fait, il y en a au moins dix voire davantage, surgissant dans le lointain. Comme les sept têtes et les dix cornes de l'Hydre de l'Apocalypse?

Entre les branches des tuyaux, derrière le chapiteau : « des observateurs? »

Figure 13 - Les observateurs, fragment de la fresque «Le Mexique d'aujourd'hui et demain » panneau gauche de l'ensemble peint au Palacio Nacional, Diego Rivera, 1935

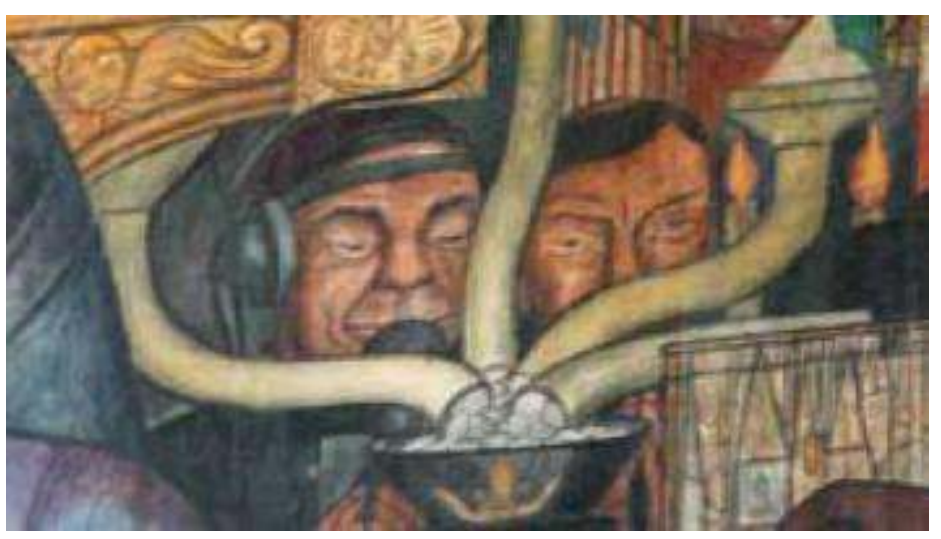

Derrière les ramifications des tuyaux issus du chapiteau de l'Eglise, apparaissent, cachés, deux hommes dont nous n'entrevoyons que les têtes. Proches des grotesques des chapiteaux romans ou des édifices à la Renaissance, elles produisent un effet comique et étrange. L'un des personnages porte un écouteur et un objet sur sa bouche, un fil sort de l'écouteur et rejoint le téléphone de l'élite mexicaine: est-il là pour donner des informations, recevoir des instructions? L'autre, dont la bouche est cachée par le tube du tuyau, épie. Il est le seul personnage à nous faire face et ses yeux ne sont pas amènes. Ces deux hommes finissent par disséminer une inquiétude chez le spectateur. Des agents de renseignements, des journalistes de la presse ou des inquisiteurs?

Poursuivons rapidement les autres enchevêtrements du réseau tubulaire en lignes droites ou en méandres, toujours en lien avec « ce lieu central ».

Deux conduits verticaux partant de la base: vers le monde du travail manuel et de l'éducation primaire. A gauche, le tube bleu s'accorde au monde ouvrier: soudeur en combinaison bleue, ouvriers courbés portant des caissons de pierres ou de briques. Il s'inscrit exactement dans l'axe vertical du tuyau central qui s'élève de l'Eglise jusqu'au téléscripteur et jusqu'au sommet où se situe Marx. A droite, un large tube blanc surgit $\mathrm{du}$ monde de la terre et des paysans. Ces derniers sont exploités par des propriétaires terriens armés. C'est dans ce monde des paysans que deux figures de l'intimité de Diego apparaissent dans un rôle éducatif et militant.

Deux conduits horizontaux : vers les moyens de répression. Le premier tube horizontal se perd discrètement pour désigner la police mexicaine montée surveillant les paysans. Le second tube au même niveau mais à l'opposé de la Grande Prostituée de Babylone, nous conduit par la grande flèche blanche à deux pendus à un arbre mort, d'une manière qui semble signifier un jugement hâtif: un paysan tenant des réformes agraires et un ouvrier communiste. Ces deux conduits horizontaux séparent, l'un, le travail agricole de la rébellion paysanne, l'autre, la rébellion paysanne de la rébellion ouvrière. 
47 L'angle blanc pointu, mais aussi les deux grosses cordes tenant les briques: vers les enseignements. L'une des cordes en diagonal conduit le regard vers l'Université, l'autre, la plus basse, le dirige vers deux hommes debout : l'ouvrier et l'étudiant portant le livre de Marx, ridiculisant les enseignements sur la doctrine du socialisme mexicain. Signalons encore ce gros tuyau blanc, partant de l'élite américaine et rejoignant un appareil très sophistiqué situé près des autorités mexicaines. Celui-ci traverse ensuite les niveaux inférieurs et semble rejoindre la caserne. Moyen de surveillance?

48 Au sommet : vers la ville ensoleillée. Au sommet de l'édifice, trois réservoirs d'usine, sombres, ressemblent à des hommes-machines; ils arrivent en contrepoint aux trois ouvriers masqué ou sans visage à la base de la fresque et paraissent veiller à la manière de gargouilles de cathédrale, en se tenant de leurs tuyaux-bras. Le plus à gauche rejoint un tuyau-bras de couleur blanche articulé à une Tour blanche élevée dans la ville ensoleillée.

Cette structure tubulaire se noue à une infrastructure de béton, rigide: elle la suit, l'accompagne, s'y enroule. Elle a permis à Diego de compartimenter les scènes.

\section{Des compartiments de verre à la création de la Ville}

Deux croquis préparatoires de Diego Rivera pour ce mural, connus, ont retenu notre attention : ils font référence à la construction d'un édifice et d'une ville. Dans celui de 1928, l'édifice est à droite, dans l'autre, ci-dessous, il est au centre gauche du dessin et il ressemble clairement à la forme finale des compartiments de la fresque. A la base, les agents économiques, des diagonales segmentent des mouvements de populations ; au sommet trois personnages sur fond d'usines; au fond à gauche, l'esquisse d'une ville. 
Figure 14 - Croquis préparatoire de la fresque « Le Mexique d'aujourd'hui et demain » panneau gauche de l'ensemble peint au Palacio Nacional

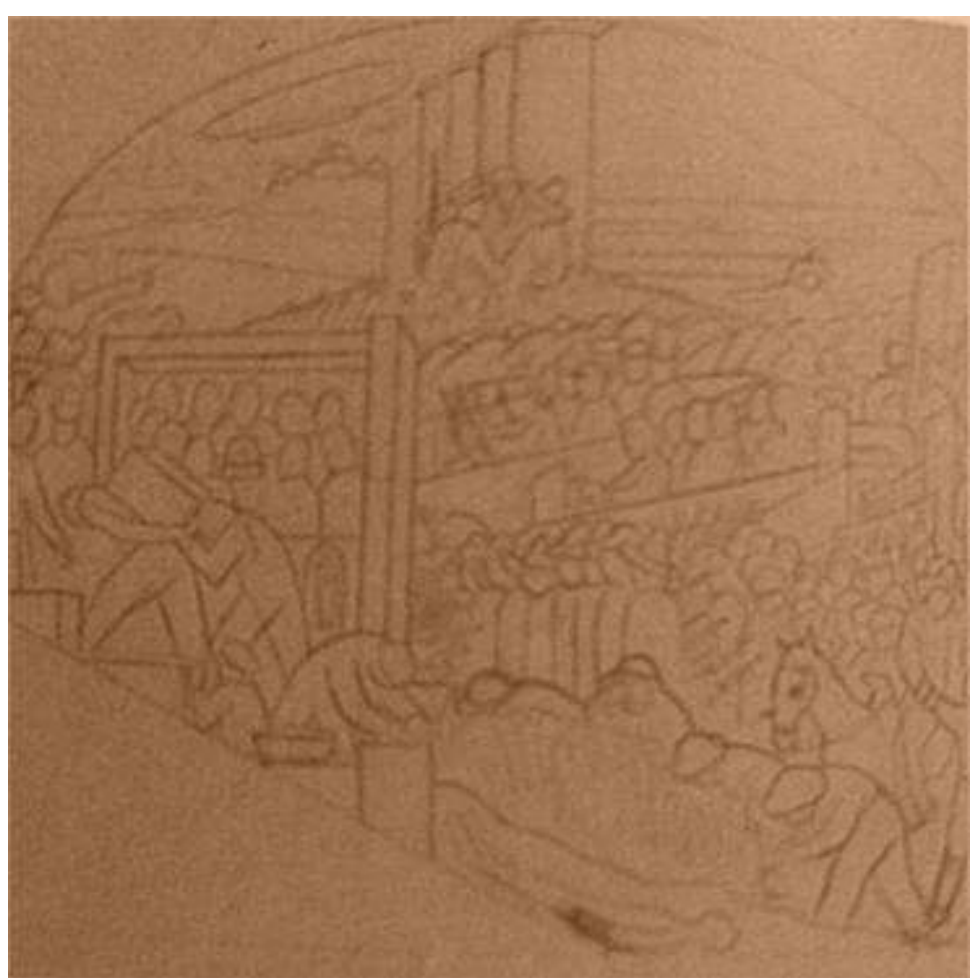

Coleccion museo universitario de ciencias y artes, UNAM, Diego Rivera, 1934 (Sánchez Hernández, 2003: 82)

51 Diego Rivera fait rentrer dans l'espace limité et fixe de la fresque finale la dynamique de la société, où s'organise la vie privée, la vie professionnelle, la vie publique, la vie sociale et religieuse. A cette fin, il crée une double structuration : d'un côté l'espace intérieur avec un compartimentage en « caissons » ou «structures de verre », de l'autre l'espace extérieur, avec la place publique, la ville ou le territoire du pays, et ses populations bigarrées, dans un mouvement apparemment désordonné.

Les divers édifices et le reste du pays sont enchevêtrés, un peu à la manière de ces dessins d'enfants ou plutôt ces miniatures du Moyen Age où toute l'organisation de la Cité se donne à voir en un raccourci saisissant. Les bâtiments s'imbriquent les uns dans les autres, formant un tout, dévoilant un monde. Ainsi la tour « de béton, de tuyaux et de verre" rassemble-t-elle l'Eglise, peut-être l'hôtel de ville, (avec ses fêtes), l'entreprise, l'Université, le palais gouvernemental du Mexique et enfin Wall Street, avec l'élite financière des USA. On y devine aussi dans le premier plan, des seuils de porte, les espaces de circulation, la rue ou le chantier de carrière (avec les ouvriers portant des caisses), les domaines agricoles (paysans), la place publique (devant l'Eglise, où a lieu la répression), la prison (derrière les pendus), l'arrière-pays où se prolongent les manifestations de révolte, de ville en ville, de territoires en territoires? La fresque traite non seulement de la spatialité mais aussi de temporalités et d'atmosphère de la ville. Dans l'arrière-plan, dans la partie embrasée comme dans la partie ensoleillée, le thème de ville est repris. La société recouvre les populations de paysans, ouvriers, réclamant leurs droits ; des constructeurs, des propriétaires terriens et des bourgeois ; des ecclésiastiques; des instituteurs, des étudiants et des professeurs; des capitalistes, des hommes politiques, des militaires ; la police, police de répression, police montée. Si 
le drapeau américain figure proche de la Vierge Guadalupe, il ne semble pas que l'armée américaine soit présente.

\section{Influences et maturation. Les Manifestes}

53 La fin du XIXe et le début du XXe sont particulièrement marqués par de nombreuX Manifestes en France. Les mouvements artistiques, le Cubisme et le Futurisme en particulier, fracassent d'une année sur l'autre une longue tradition. L'un et l'autre sont nés des bouleversements liés à l'industrialisation, l'électrification, les machines, la vitesse nouvelle. Diego subira cette attraction lors de son séjour en Europe, et surtout aux USA ; ses échanges avec son ami Elie Faure en témoignent. Toutefois, il nous semble utile de revenir à l'expérience européenne de Diego Rivera, pour mieux comprendre ce qu'il retient comme enseignement et ce dont il s'éloigne.

Le Cubisme et la rupture avec l'assise de la ressemblance : «le B...»! En se rendant à l'Exposition Universelle de 1900 à Paris, Picasso découvrit brutalement la modernité urbaine, avec l'industrie, les ornements métalliques de l'art nouveau, l'électricité. «Picasso se cogne au XXe siècle d'une manière qu'il ne pouvait pas soupçonner $»^{45}$. Mais ce choc se traduit, après maturation, dans son œuvre intitulée "Les Demoiselles d'Avignon", exposée en 1907. Aujourd'hui, nous ne pouvons plus guère nous représenter le scandale que provoqua Picasso avec cette œuvre. Il faut entendre sa compagne Fernande: «Ce fut un cataclysme!». En abandonnant la figuration et la ressemblance du visage, au profit d'un art abstrait et anonyme, avec des lignes brisées, telle une architecture métallique brutale, mais aussi, en introduisant l'idée d'un métissage avec l'art nègre ${ }^{46}$, Picasso provoque un choc qui fait sentir tout le poids de règles sociales qu'on ne franchit pas aisément. L'imitation fidèle du visage de l'être humain ${ }^{47}$ est requise tant par les traditions religieuse, artistique et académique, que par les exigences scientifiques (médecine, anthropologie, ethnographie). Nous nous situons encore dans un contexte de tensions sur les identités et les races ${ }^{48}$. Nous nous situons aussi dans un contexte où, après la loi de 1905 sur la séparation de l'Eglise et de l'Etat, la lutte entre cléricaux et anticléricaux est sévère. Diego Rivera ne peut ignorer ces affaires. S'il admire Picasso, s'il s'exerce au cubisme ${ }^{49}$, il s'en éloignera cependant. Mais il nous faut retenir cet événement, et se ressouvenir que l'œuvre de Picasso s'intitulait alors «le Bordel ». De quoi parlait au fond Picasso ? Pierre Daix l'associe à la réplique de Rimbaud d'une Saison en Enfer " Un soir, j'ai assis la beauté sur mes genoux - Et je l'ai trouvée amère. - Et je l'ai injuriée ». Nous reviendrons sur l'énigme. Il faut aussi se ressouvenir que les deux hommes furent à la fois amis et rivaux.

Le Futurisme, le Stridentisme, ces deux mouvements sont fascinés par le progrès machinique. Le Futurisme, aspiration au progrès permanent, pose un programme de renouvellement d'une humanité magnifiée par le progrès machinique; il est destiné à «une nation jeune» et, pour Marinetti, Italien, celle-ci est «embarrassée par son héritage historique glorieux». Et «En avant, toujours plus vite, plus loin, plus haut pour rénover (lyriquement) la joie de vivre». Quelques extraits du Manifeste de Marinetti, paru dans le Figaro du 20 février $1909^{50}:$ "Il n'y a plus de beauté que dans la lutte. Pas de chef-d'œuvre sans caractère agressif. " "Nous chanterons les grandes foules agitées par le travail, le plaisir ou la révolte; les ressacs multicolores et polyphoniques des révolutions dans les capitales modernes; la vibration nocturne des arsenaux et des chantiers sous leurs violentes lunes électriques (...) « Nous sommes sur le promontoire extrême des siècles! A quoi bon 
regarder derrière nous, du moment qu'il faut défoncer les vantaux mystérieux de l'impossible?».

Les idées du Futurisme et du Dadaïsme franchiront l'Atlantique. Inspiré par celles-ci, un mouvement émergera au Mexique, le Stridentisme. Cet avant-garde artistique, composé surtout par des poètes tels que Manuel Maples Arce, Salvador Gallardo, Germán List Arzubide, Arqueles Vela et Luis Quintanilla, eut une prédilection pour les sujets urbains, la ville, les machines, l'industrie et les usines. Ainsi Maples Arce chante dans son manifeste le « régime industrialiste des grandes villes trépidantes et des blouses bleu des ouvriers ».

Figure 15 -» Actual, feuille d'avant-garde et comprimé stridentiste » de Manuel Maples Arce à Mexico (1921), un des premiers manifestes avant-gardistes d'Amérique Latine

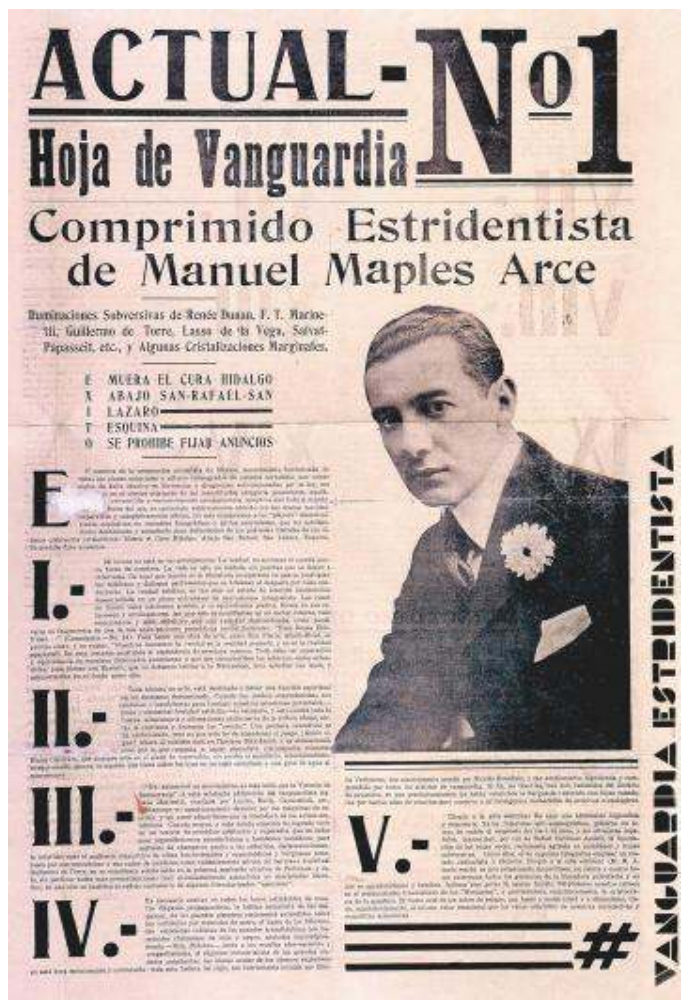

Diego Rivera, qui a fréquenté les futuristes ${ }^{51}$, n'a pas pu ignorer ces Manifestes. Sa grande œuvre prend à son tour acte des idées nouvelles. Mais si Diego Rivera en retient l'idée et le mouvement ${ }^{52}$, force est de constater que celui-ci se démarquera de «l'abstraction pure et simple ». Il nous semble même en prendre le contre-pied. On ne peut pas dire que Rivera n'a pas intégré « le coup de poing à donner » ni qu'il ne prit pas de risques! Mais n'est-ce dans un sens différent de celui que prononce l'Italien, Marinetti. Nous avançons qu'il ne s'agissait pas de donner un coup de poing à «un héritage glorieux » mais à " un héritage humiliant et mal vécu » ${ }^{53}$. Ce dernier n'aurait-il contribué à une prise de conscience chez Rivera, à ce qu'il retourne aux sources de l'histoire du Mexique et qu'il décide la création d'une collection majeure de l'art précolombien? Ne se distancie-t-il pas du Manifeste du Futurisme, en adoptant de fait, de la Renaissance italienne et le classicisme, les valeurs d'une tradition humaniste, européenne, et aussi en s'intéressant à l'héritage culturel aztèque et aux traditionnelles techniques artisanales? Dans le même ordre d'idée, au lieu « d'effacer ou de briser les visages et les corps ", n'a-t-il opté, au contraire, pour un style figuratif " protubérant ». 
Le but n'était-il pas de rendre visibilité "à des visages et des corps " de façon magistrale, afin de valoriser les identités des Effacés et Anonymes d'un Empire au destin brisé par l'Histoire? Diego s'en tient à la ressemblance, qu'il s'agisse de personnes ou de types ${ }^{54}$ : l'indien, le paysan, l'ouvrier, la femme, l'esclave, et, avec tendresse, il les magnifie dans leur humble vie quotidienne, tout en en retraçant aussi leur oppression inacceptable. En d'autres termes, "un coup de poing», mais en direction de ceux qui furent ou étaient alors les oppresseurs, et la tentative de rendre justice à ces hommes et ces femmes du peuple, massacré, asservi, brisé.

D'autres influences majeures se feront sentir, issues des Révolutions du prolétariat, russe et mexicaine et de l'espoir lié à la nouvelle Constitution mexicaine de 1917. Diego Rivera se détourne du cubisme et de courants avant-gardistes, car il considère la peinture au chevalet comme un art «bourgeois $»^{55}$, réservé aux privilégiés, et dès lors, il l'abandonne au profit de l'art mural, avec le souci d'éducation du peuple mexicain. Cette rupture intervient dans les années 1917-1919. "Grace aux fresques des peintres italiens, depuis les byzantins jusqu'à Michel-Ange, il avait trouvé la réponse aux exigences d'un art populaire, qui fût en mesure (...) de donner naissance à une peinture sociale et monumentale. $\|^{56}$

Enfin, après le choc de la première guerre mondiale, l'événement de la Révolution russe en 1917, il se produit, dès les années1921-1922, à Paris mais aussi dans les différents pays d'Europe et en Russie, « un retour à l'ordre » sur le plan artistique ${ }^{57}$. Le marxisme, la Révolution russe, l'exil d'artistes provoquent d'amples débats dans les milieux artistiques fréquentés par Diego Rivera à Paris, d'autant que sa compagne est russe ${ }^{58}$. A partir de 1922, l'art abstrait, tout comme l'art des icônes, sont en effet interdits en Russie et ses effets se font sentir surtout vers la fin des années vingt ${ }^{59}$. Pour les autorités politiques, l'art abstrait était trop éloigné du peuple et les icones ressortent du domaine de la superstition antirévolutionnaire. Il s'agit de magnifier le travail, l'économie et la Révolution. Diego Rivera, profondément marxiste, participe à ces débats politiques, et pourtant, le parti communiste ne manquera pas de le mettre en difficulté sur le plan artistique. Diego s'oppose à une " volonté de déraciner le passé " ${ }^{60}$. Selon Pierre-Olivier Douphis, celui-ci revint déçu de son voyage en URSS en 1928, tant par une politique opprimant les libertés que pour un art restrictif, imposé par des autorités politiques, contre la personnalité du créateur et contre des arts traditionnels, reflets d'une piété simple et ancestrale.

\section{Diego et l'impact de la technologie dans l'art}

60 Tout comme Picasso, Rivera a reçu le choc de l'urbanisation et de l'industrialisation, il a été émerveillé par les machines, fasciné par l'architecture de ces nouvelles métropoles, en Union Soviétique et surtout aux USA. Les nombreuses fresques marquantes de Rivera magnifient le travail, la machine, l'économie et les hommes, ingénieurs ou ouvriers, qui construisent la ville moderne.

61 Par son ami Elie Faure, médecin, écrivain et théoricien de l'art, Diego est conforté dans son approche de la machine. Tandis qu'il élabore sa peinture murale, en 1933 il reçoit une longue lettre d'Elie Faure ${ }^{61}$ à propos de la machine et de son rôle dans la vie moderne. Celui-ci donne son appréciation sur les fresques de Détroit et les vues qu'elles ont développées dans son esprit à partir des graines que Diego y avait semées une quinzaine d'années auparavant: «Ce que tu me dis des Etats-Unis vaut mieux que ce qui se 
passe ici en France. La machine est devenue l'ennemi ; tous les écrivains, peintres et dramaturges l'accablent d'anathèmes bourgeois. Quos vult perdere... ". Ainsi Elie Faure analyse-t-il en France : «C'est le règne de la terreur. Le bourgeois recule devant son enfant monstrueux, dont le peuple est en train de prendre possession. Quel admirable spectacle !... Pendant ce temps, les imbéciles acclament au Théâtre Français une pièce qui dénonce la machine. Remarque qu'ils ont réservé leur place par téléphone, qu'ils admirent les acteurs avec des jumelles, que leur automobile les attend au coin, qu'ils sont allés au cinéma la nuit précédente, et que demain, les chirurgiens armés de sondes électriques stérilisées en autoclave trépaneront leur enfant. Misérables idiots! Tu ne peux pas savoir le plaisir que j'éprouve à te voir utiliser la machine comme source d'émotion plastique et de décoration dans tes nouvelles fresques, qui me semblent puissamment belles, même s'il y manque l'élément couleur que j'admire tant. » (Wolfe, B., 1994 : 228-229)

Entre 1933 et 1935, Rivera gère de front diverses fresques mettant en scène la technologie. Ainsi réalise-t-il les fresques valorisant la technologie dans « L'industrie de Détroit » (1933-1934) ${ }^{62}$, et, à Mexico « L'homme qui contrôle l'univers » (1934) ${ }^{63}$. Inspiré par le travail du peintre mexicain, Elie Faure traduira sa vision de l'ère moderne et la puissance de l'homme appelant aux nouveaux sujets et aux nouveaux motifs d'émotion : "féerie des usines, des gares, des chantiers, des arches illuminées sur l'océan, des tours babyloniennes sur les villes $"^{64}$.

63 Toutefois, Diego a affronté à New York en 1931 la misère liée à la crise financière et a assisté à Détroit en 1932 à des grèves d'ouvriers des usines Ford suivies de violentes répressions et qui l'ont impressionné65. Cette période (1929-1935) est encadrée de deux échecs, Diego Rivera ne supportant pas les injonctions des autorités politiques envers son art. D'un côté, le Parti Communiste Mexicain, d'obédience soviétique, l'a exclu en 1929, alors que la révolution soviétique a pu lui inspirer ses grandes thématiques. De l'autre, aux USA, le pays dont il admire les formidables révolutions, techniques et architecturales, son commanditaire fait détruire la peinture qu'il a réalisée pour le Rockfeller Center, en février $1935^{66}$.

La fresque «Le Mexique aujourd'hui et demain », présente des différences par rapport aux œuvres précédentes ; une autre conscience s'y exprime. Force est de constater que l'artiste n'est pas disposé à soumettre son travail artistique aux directives d'une idéologie politique déterminée. S'il manifeste une sensibilité au monde des ouvriers, il porta aussi un grand intérêt au monde paysan et à la solution de leur problème ${ }^{67}$.

\section{PARTIE II}

\section{Technologie, arts et mythes. Icône du téléscripteur et culte de l'argent}

La vénération dont est entourée «le micro-objet » de la part de la plus haute sphère politique ne peut pas passer inaperçue et la manière dont Diego Rivera représente plastiquement le téléscripteur " avec des erreurs » mérite attention ${ }^{68}$. De plus, au sein de ce compartiment, les ramifications, curieusement disposées, les papiers serpentant, le tuyau-colonne coupant la scène en deux, formant une croix avec en son sommet des inscriptions, tous ces signes rassemblent en un seul tableau les éléments du culte catholique chrétien, tout en les détournant au profit d'un culte du dollar et d'un fascisme. En effet, la colonne coupant la scène en deux nous évoque la colonne de 
scènes de l'Annonciation, et particulièrement celle de Lorenzetti et de Fra Angelico : les paroles peintes en or de l'Ange Gabriel et celles de Marie circulent autour de la colonne; la colonne incarne Dieu, elle dit que Dieu est déjà incarné ${ }^{69}$. La colonne devient dans le même temps la Croix où Jésus est crucifié ; l'inscription le désignant « roi des Juifs » est muée en symbole du dollar et du fascisme (et du svastica); enfin, le téléscripteur ressemble davantage à un sarcophage, au mont Golgotha, à une montagne sacrée, et à un tabernacle. Cette icône d'or avec son aura vient en symétrie et en opposition avec la petite icône de la Vierge de Guadalupe. Et les banderoles développent non les paroles d'or mais les chiffres de l'or. De façon drastiquement raccourcie, Diego met en place "un simulacre" de l'annonciation, l'incarnation, la communion, la crucifixion, la mort, la résurrection. Le téléscripteur devient une sorte d'idole, introduisant l'idée d'un nouveau culte : le culte de l'argent.

66 Ainsi Diego Rivera traduit-il plastiquement en 1934-1935 les signes extérieurs de ces nouveaux cultes du capitalisme, tout comme Aragon les traduit littérairement, en termes admirables ${ }^{70}$, dans le Paysan de Paris, publié en 1926. Cette idée de culte posée par Rivera s'exprime aussi dans une tradition à laquelle a donné naissance le téléscripteur : des fêtes publiques.

La haute finance n'a pas opéré en des lieux hermétiquement clos. De nouvelles traditions de fêtes sont nées avec le téléscripteur et les informations boursières. Le téléscripteur s'inséra dans les espaces publics des Etats-Unis. Il a donné naissance à de curieuses fêtes en Amérique du Nord, en Italie mais aussi en l'Amérique Latine, tout particulièrement dans les quartiers des affaires. Cette fête se déroule, à la fin de l'année ou lors de la visite des hôtes officiels. Ainsi, de toute part, depuis les fenêtres des immeubles étaient lancés dans les rues les fameux rubans sur lesquels s'affichait le cours des actions en continu pendant l'ouverture des marchés boursiers. (Photo ci-dessous). Cette fête a débuté avec la popularisation de l'appareil, vers la fin du XIXe siècle. Entre 1921 et 1929, pour favoriser la démocratisation des activités financières, des téléscripteurs furent installés dans les salons de coiffure, les trains, les bars. 
Figure 16 - La ticker tape parade (défilé de la bande de téléscripteur) à Chicago marque l'arrivée d'Apollo 11 sur la lune, en juillet 1969

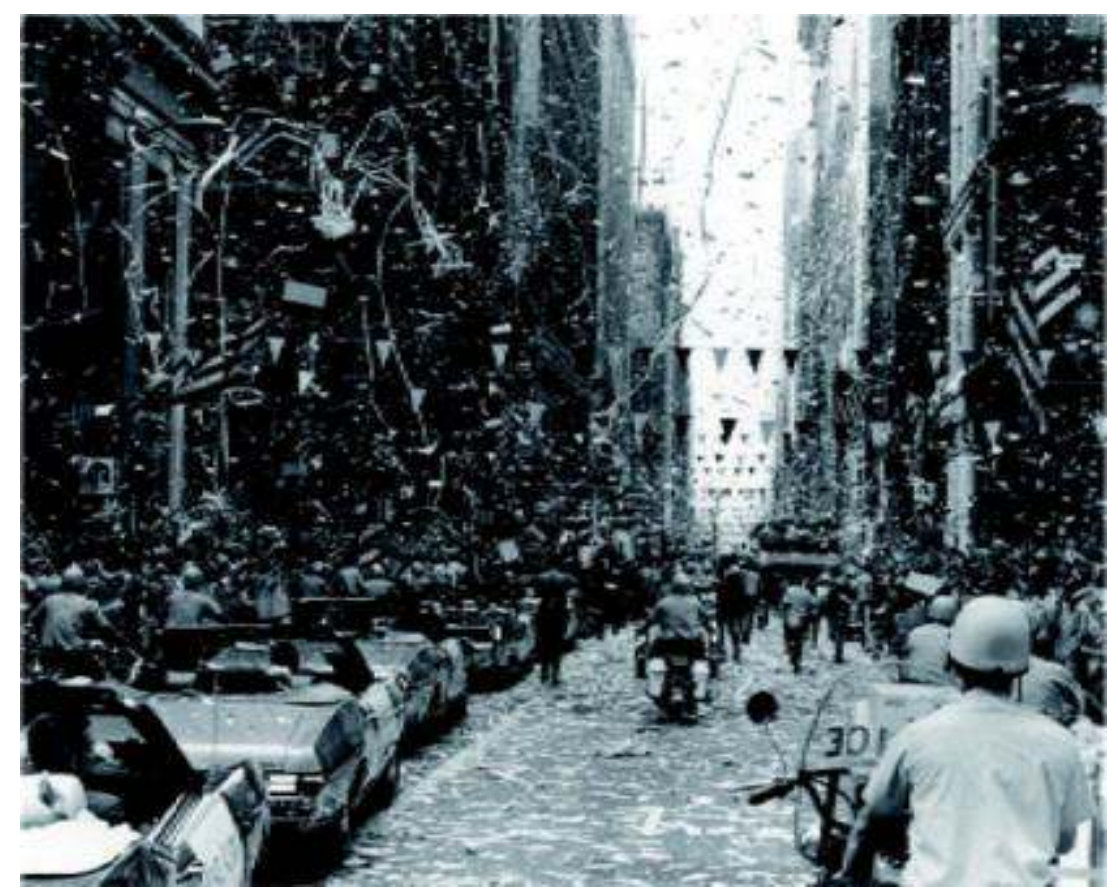

Photo de la NASA

Wall Street et le développement d'un empire technico-économique et financier produisent de nouveaux cultes et des cérémonies rituelles. Diego, marxiste, les expose à sa manière et dénonce le fétichisme de l'argent et ses faux cultes.

\section{Technologie et grands mythes}

Ces fêtes autour du téléscripteur et ses rubans chiffrés des résultats de la Bourse, avec leur insertion dans la vie quotidienne, participent à la fois d'une nouvelle croyance en un système économique moderne et à l'élaboration d'un nouvel imaginaire urbain. Rappelons que le système s'est enrayé, provoquant la crise de 1929, la dépression entraînant faillites, drames et misère parmi la population. Des manifestations furent réprimées par la force. L'artiste veut marquer la perversité du système politico-économique qui s'est mis en place. Et ne le présente-t-il sous l'aspect d'une structure banale et monstrueuse en ses tentacules? Structurée par les tuyaux, la Bourse et le système capitaliste ne constituent-ils une sorte de monstre invisible mais soudainement personnifié par des forces répressives noires d'où émergent des têtes d'hydre. Les masques, parfaitement visibles avec leurs yeux protubérants et leur tuyau à anneaux parmi les forces répressives (sur la droite de la fresque) sont identiques à ceux des usines de fabrication d'armes toxiques ${ }^{71}$. L'hydre semble même se prolonger en d'autres lieux. Ce monstre aux têtes nombreuses issu des méandres tubulaires est relié à l'empire de Wall Street. Une binarité s'observe entre ces masques en forme de têtes d'hydre et le masque de soudeur porté par l'ingénieur en premier plan, tel un paradigme du bien et du mal et le paradigme d'un fonctionnement du système partagé entre production et répression. 
Le serpent est ancré dans toutes les grandes traditions millénaires, avec des attributs et des caractéristiques différents. Le serpent est aux côtés d'Ishtar, à Babylone ; il est dans la Bible, avec Adam et Eve, provoquant leur exil du Paradis ; on retrouve sa présence sous les pieds de la Vierge Marie; enfin, il appartient à la culture aztèque et Diego l'a souvent représenté dans les fresques du Palacio Nacional. Il était encore prévu dans les croquis préparatoires de cette fresque. Mais il s'est mué en autre chose. Une autre comparaison s'est imposée à partir du Livre de l'Apocalypse. Dans la version de St-Jean, la vision présente : « une femme assise sur une bête ayant sept têtes et dix cornes »".

Figure 17 - La grande Prostituée de Babylone boit à la coupe, Miniature anglaise du XIVe siècle

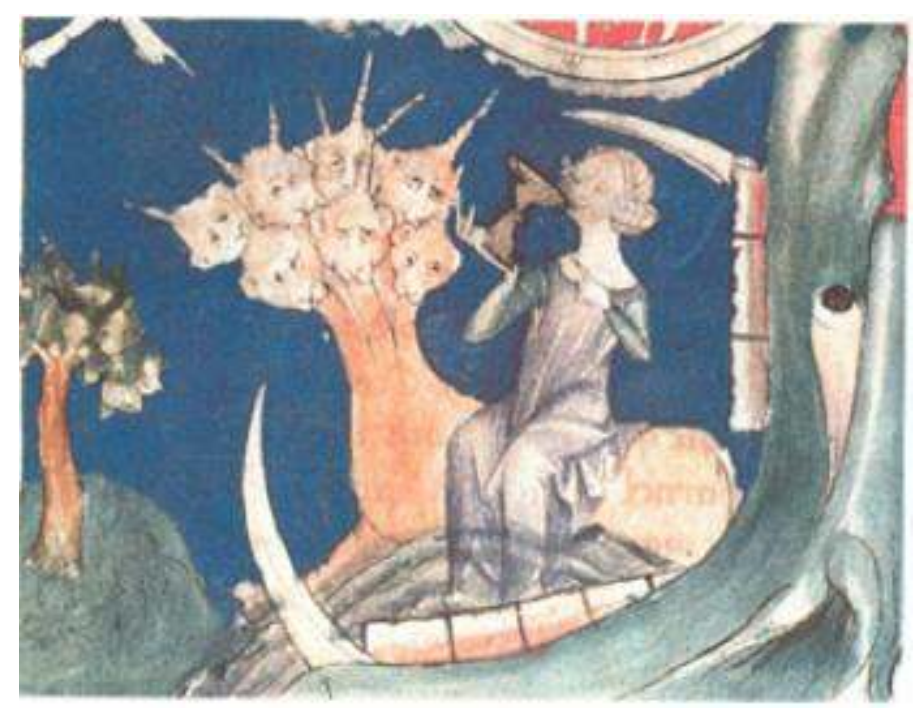

Lincoln College, Oxford

71 Comme nous l'avions énoncé dans le précédent chapitre, l'échafaudage tubulaire en méandre est une structure et aussi un moyen de conduire le regard vers des "noyaux " signifiants: système économique, financier, universitaire, système répressif; le système religieux est une partie maîtresse intégrée aux autres éléments de l'ensemble. Dans la fresque, le peintre pose un regard acerbe sur la fonction religieuse traditionnelle, dans un contexte où la religion est très prégnante au Mexique.

L'anticléricalisme a particulièrement marqué la période de 1924 à $1928^{73}$, et même si le gouvernement de l'époque tente d'apaiser ces luttes, la religion chrétienne fait l'objet de questions.

Fête ou questionnement sur le dogme chrétien? Le tuyau 2 de notre démonstration nous introduit à la scène scabreuse entre un prêtre et une belle femme, dans le « compartiment» d'une scène bourgeoise. Lowy évoque : «des bourgeois dans «leurs occupations quotidiennes ", "une fête/orgie où l'on boit du champagne, et où un prêtre est en train de s'amuser avec une prostituée (...) ». La scène traduit manifestement un ennui, un malaise, témoigne d'un embarras, une situation où les gens voient, savent, mais se taisent. Le dogme du célibat des prêtres pourrait-il être au cœur d'un questionnement et de cet embarras, de même, le mariage et ses interdits religieux ?

Guerre anticléricale? Modèle artistique de provocation? La présence de ce couple, le prêtre et la prostituée ne s'insère-t-elle pas dans le cadre de la féroce querelle anticléricale, muée en "guerre anticléricale » dans l'histoire du pays ${ }^{74}$ comme au sein 
de la fresque par l'importance des pamphlets sur l'Eglise et les textes portés par les deux femmes, Frida Kalho et sa sœur, dans leur rôle éducatif. Athée, Diego Rivera, aux aventures donjuanesques, affiche son anticléricalisme et celui de son milieu ambiant. Mais aussi, cette scène provocante ne s'inscrit-elle dans une lignée de mouvements artistiques « révolutionnaires » de l'avant-gardisme ? En d'autres termes, Diego Rivera n'a-t-il saisi et ne répète-t-il pas, à sa manière, une geste fondamentale de la révolution cubiste. Picasso n'a-t-il donné le ton avec la création artistique qui fit scandale en 1907 «le Bordel $»^{75}$, inspirant dès lors, et tour à tour, un modèle de provocation. Les premières œuvres exposées d'Orozco, avec qui Diego Rivera signa le Manifeste de l'art révolutionnaire en 1921, concernent la prostitution (Casa de lagrimas, 1915) ${ }^{76}$. Nous laissons la question ouverte sur les multiples sens que peut recouvrir cette mise à nu. De nos jours, dans un contexte de libéralisation des mœurs, où tabous et interdits sont levés, où la nudité des corps de femmes est exposée sur les murs publicitaires ${ }^{77}$, le regard du spectateur peut s'arrêter à l'idée du plaisir lié à la sexualité et à celle de la prostitution sexuelle, soit le culte du sexe. Cette vitrine du sexe ou vitrine, machine à désir et à fantasme, imposée, participe-t-elle d'une sémiotique en contrepartie de la répression?

Toutefois, cette scène, la taille monumentale que donne Diego à la « prostituée » nous a évoqué un thème autrement puissant. En effet, cette icône ne renvoie-t-elle pas en termes visibles et hermétiques, à " la Grande Prostituée de Babylone » de l'Apocalypse de Saint-Jean? Le livre de l'Apocalypse est un livre qui a connu un retentissement prodigieux, tant dans la communauté chrétienne que bien au-delà de celle-ci, dans le monde entier; les artistes se sont emparés de cette thématique, le plus souvent, commandités par les hommes d'Eglise. De nombreuses représentations dans les églises et sanctuaires, les manuscrits précieux avec miniatures, les tapisseries, en retracent

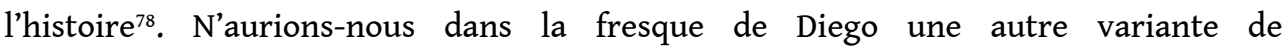
l'Apocalypse ? Dans les visions de Saint-Jean, la Grande Prostituée est identifiée assise sur une bête à plusieurs têtes, à sept têtes, telle une hydre, et sur les eaux. Elle est identifiable avec ces caractéristiques : elle est riche, elle se livre à la prostitution avec les rois de la terre; elle a une dette de sang. Dans l'Apocalypse de Saint-Jean, texte destiné à des initiés, l'idée de corruption et de prostitution se réfère plus à la politique qu'au sexe ${ }^{79}$. De nombreux écrits insistent sur la dénonciation des pouvoirs politiques à travers l'Apocalypse. La Prostituée de Babylone se livre à des complicités avec les pouvoirs politiques, les puissances d'argent, pour assoir sa position et sa renommée. Mais il est vrai aussi que les artistes, au cours du temps, ont davantage représenté la prostituée de Babylone «sous des aspects sinistres ou fastueux plutôt que sa signification politique ou historique $»^{80}$.

La femme prostituée de l'Apocalypse est souvent identifiée comme étant l'Eglise catholique romaine. Or, dans la fresque, Rivera ne nous indique-t-il pas que cette femme représente l'Eglise ou plutôt une certaine Eglise par divers signes. La femme dans la simplicité de son appareil repose sur l'édifice de l'Eglise comme sur un riche trône, le chapelet avec sa croix dans sa main. C'est cette Eglise que le prêtre tient par la main et embrasse ${ }^{81}$, mais dans un sens métaphorique envisageable. 
Figure 18 - Détail de l'icône de la prostituée de la fresque « Mexique d'aujourd'hui à demain » au Palacio Nacional à Mexico. Diego Rivera, 1935

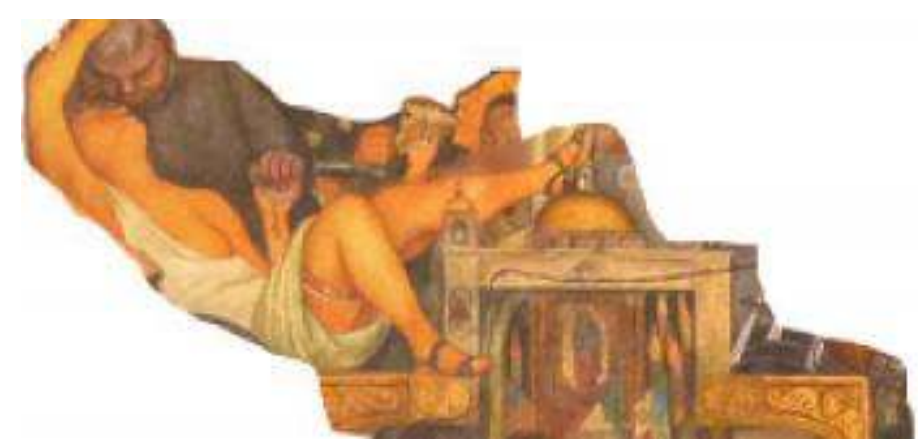

Diego Rivera nous oppose sans cesse des binarités : à la croix de l'Eglise s'oppose la croix du chapelet de la femme prostituée ; à l'icône de la femme bien en chair, géante, impudique, répond la modeste icône de la vierge de l'autel de Guadalupe. Ainsi le peintre nous montre-t-il une Eglise à deux visages : une Eglise «intérieure », invitant au recueillement et à une spiritualité intime (avec la Vierge de la Guadalupe) et une Eglise "extérieure", qui se manifesterait avec faste, tenue par ses régisseurs, la hiérarchie des prêtres et s'exposant «naturellement » à la vue de tout le monde . Cette idée de Grande Prostituée de Babylone n'est pas sans prendre force et sens lorsque l'on lit parallèlement le tableau et les textes de l'Apocalypse. Nous en donnerons quelques exemples.

Le livre de l'Apocalypse de St-Jean : «Les eaux que tu as vues, sur lesquelles la prostituée est assise, ce sont des peuples, des foules, des nations et des langues. ${ }^{82}$. A cette phrase pourrait correspondre dans la fresque, l'attitude de la prostituée qui repose non seulement sur un trône tenu par les «liquidités", mais aussi sur le dos de travailleurs ouvriers transportant de lourds caissons de briques, participant aux fondations de l'édifice. Le Mexique est composé de nations, de langues et de cultures différentes.

79 "Cette femme était vêtue de pourpre et d'écarlate, et parée d'or, de pierres précieuses et de perles. Elle tenait dans sa main une coupe d'or, remplie d'abominations et des impuretés de sa prostitution ». "La grande prostituée qui corrompait la terre par son impudicité»"83. Dans la fresque, c'est l'impudicité qui est exposée et la prostituée échange de l'argent avec le prêtre. Une coupe de champagne apparaît à ses côtés, bue par une femme dont le bras croise la jambe de la prostituée. La femme Eglise est installée du côté des puissants, près des bourgeois.

Le livre de l'Apocalypse de Saint-Jean : "C'est avec elle que les rois de la terre se sont livrés à l'impudicité ", "et c'est du vin de son impudicité que les habitants de la terre se sont enivrés " ${ }^{84}$. Dans cette hypothèse, la fresque pourrait encore désigner une Eglise alliée aux puissances d'argent, aux pouvoirs politiques et aussi aux pouvoirs répressifs.

81 L'Apocalypse de Trèves, du IXe siècle, offre une image de la grande Prostituée, assise sur les méandres de la bête en forme de serpent-fleuve, qui s'inscrit étrangement en perspective isomorphique avec le schème des canalisations de Rivera ${ }^{85}$. 


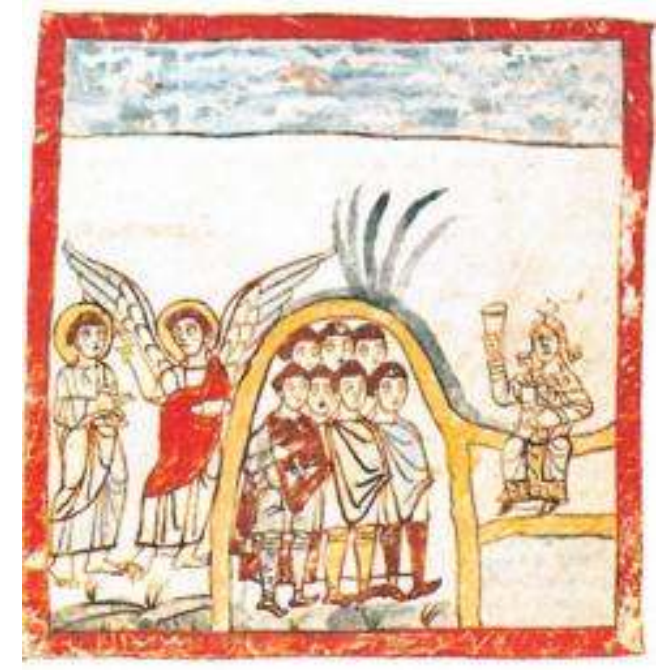

La religion chrétienne est fortement ancrée au Mexique. Le catholicisme s'incarne dans la figure de la Vierge de Guadalupe, protectrice des Indiens et des métis ${ }^{86}$. Négligeant peut-être une authenticité de cœur et de spiritualité humble et profonde, Diego Rivera ne voit en ces femmes pieuses, - qui par ailleurs semblent épiées, surveillées, par des observateurs en lien direct avec les plus hautes autorités du pouvoir mexicain - que des personnes inintelligentes, trompées par le pouvoir capitaliste et abusées par le système politico-religieux.

Ainsi ces églises, intérieure et extérieure, sont-elles placées sous le feu de la critique du peintre $^{87}$. Dans sa fresque, ne les condamne-t-il pas toutes les deux : l'Eglise intérieure, sans réflexion et sans intelligence ; l'Eglise extérieure, intelligente, rusée, " sans cœur, sans compassion » et perverse. Ce serait une Eglise retournant les valeurs de sa propre source, une Eglise qui n'assurerait pas un véritable magistrat à l'égard des populations. Où est la « vraie Eglise »? Quelle issue propose-t-il ?

\section{Réalisme socialiste, art chrétien et art marxiste}

Le marxisme, une nouvelle « croyance »? Diego, à travers la fresque, fonde l'espoir en un avenir différent par la formation des individus, des gens du peuple, ouvriers ou paysans, hommes ou femmes. L'action repose sur les instituteurs à la base (Frida Kalho et sa sœur dans un rôle éducatif), militants anticléricaux, ou les étudiants (à gauche), critiquant les enseignements de l'Université, celle-ci étant vue comme appartenant au système fonctionnel des pouvoirs politiques. Le marxisme, éclairant les rouages du capitalisme, l'aliénation des peuples, se veut cristalliser une nouvelle foi en l'homme afin qu'il prenne lui-même son destin en main. Les attitudes de ces personnages porteurs de cette foi n'échappent pas à une rhétorique religieuse : la femme en bas de la fresque, adossée à la colonne du tuyau, paraît agenouillée ; le libre penseur sur la gauche tient le livre de Marx comme une Bible. Ils se situent en marge du système central. Enfin, Marx lui-même, sur la montagne des usines, adossé aux tuyaux sombres des usines en contrepoint des tuyaux blancs, présente le Capital avec les Tables de la Loi d'un Moïse, annonçant une nouvelle société à fonder. 

marxisme fait notamment l'objet d'une rhétorique issue de la Bible, des Evangiles du catholicisme surtout. Nous prendrons ici deux exemples: un long discours de Jean Jaurès, journaliste et homme politique, fondateur de l'Humanité, co-directeur de la section française de l'Internationale ouvrière avec le marxiste Jules Guesde, et une image de Marx qui a circulé en carte postale. Ainsi, le discours de Jean Jaurès : «C'est donc une transposition hégélienne du christianisme que Marx se représente le mouvement moderne d'émancipation. De même que Dieu s'est abaissé au plus bas de l'humanité souffrante pour relever l'humanité toute entière (...), de même dans la dialectique de Marx, le prolétariat, le Sauveur moderne, a dû être dépouillé de toute garantie , dévêtu de tout droit, abaissé (...) pour relever en se relevant toute l'humanité $"{ }^{90}$.

Ainsi, le Marx Moïse moderne: Nous nous référons à une image publiée ${ }^{91}$ avec un article dans le Monde portant sur "Karl Marx l'irréductible, une vie, une œuvre », publié en décembre 2011. Cette carte postale, anonyme, a été diffusée en 1900 ; elle a pour titre "Marx - Le Moïse moderne ». Elle représente la caricature de Marx en Moïse moderne, debout sur le Mont Prolétarien, tenant les Tables de la Loi «le capital, manifeste communiste ». Enveloppé de l'éclat brillant d'un soleil, dont les rayons font jaillir « des paroles ", il domine, entouré des prolétaires de nombreux pays d'Europe et du monde portant chacun leur drapeau. Les termes, en français «Le Moïse moderne » au-dessus de l'image, sont traduits tout en bas en allemand, anglais, russe et hébreux ». Cette 
image diffusée sous forme de carte postale conforte bien cette rhétorique, quand bien même les marxistes se proclament athées.

Figure 20 - Photo de Marx en « Moïse moderne ». 1900

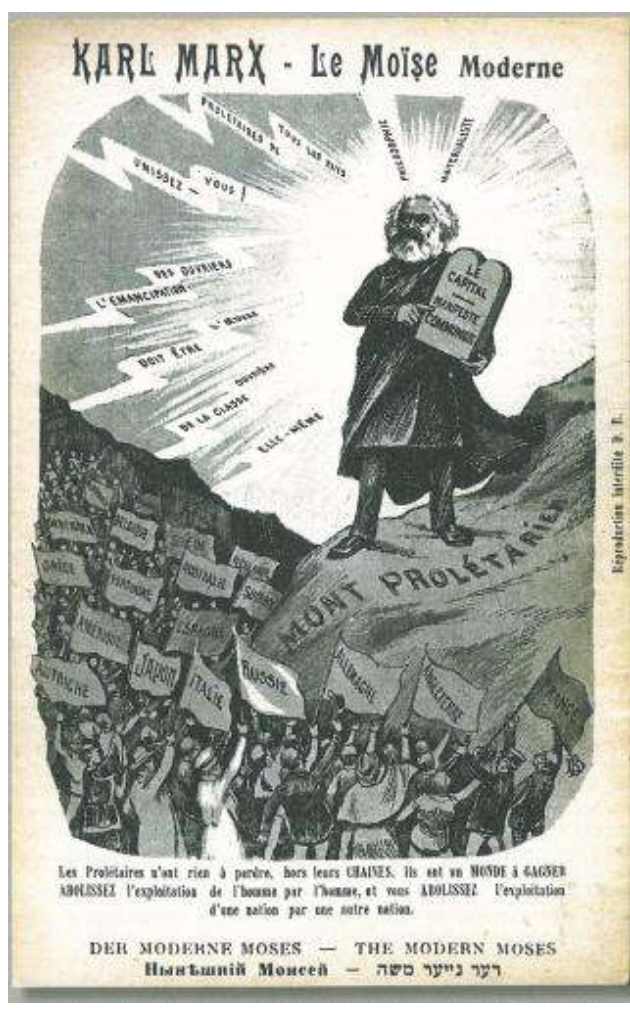

Cette carte postale n'est pas sans rappeler la représentation de Marx, dans la fresque. Toutefois, le soleil derrière lui irise des langues de feu qui ressembleraient davantage aux langues de feu du serpent représenté dans la peinture murale «México prehispánico - El ántiguo.mundo indígena » de 1929.

Ces références étaient encore en vigueur dans les années trente et se sont prolongées plus largement, chez bien des militants communistes. Il faut aussi tenir compte de l'engagement de Diego Rivera, dès les années vingt, à l'ordre des Rosicruciens ${ }^{92}$. B.D. Wolfe par ailleurs mentionne clairement que Diego ne renie pas une influence de l'art chrétien ${ }^{93}$. Les fresques humanistes et bibliques de la fin du Moyen Age et de la Renaissance ont été un ressort puissant.

Pierre-Olivier Douphis ${ }^{94}$ offre également des pistes à cette réflexion sur l'art chrétien et les mythes. Dans son analyse des murales de Chapingo, à l'Escuela nacional de Agricultura de Texcoco, réalisées dans le même intervalle de temps que le ministère de l'Education, entre 1925 et 1928, il montre l'importance des références religieuses chez Diego Rivera : "Les peintures laïques doivent contrebalancer l'influence de l'Eglise, tout en se servant des mêmes recettes formelles $» .^{95}$ Patrick Marnham, quant à lui, qualifie les convictions de foi à travers les œuvres de Diego Rivera de "parareligieuses $»^{96}$. Luiz Martin Lozano donne aussi son point de vue ${ }^{97}$. La religion chrétienne, imposée au Mexique depuis le XVIe siècle, est-elle encore assimilée aux colonisateurs? Il ne faut pas négliger le moment où se situent ces réalisations : face au monopole économique et culturel de l'Europe et des Etats-Unis, le Mexique se cherche une identité. Ainsi, Rivera, se faisant l'interprète des révolutionnaires, s'est-il aussi tourné vers les racines 
historiques du pays, en s'appuyant sur la précieuse référence du dieu serpent à plumes. Sa vision de la modernité et d'un monde meilleur n'exclue ni l'art religieux ni les mythes. Pour Pierre-Olivier Douphis, ces œuvres participent des prémices d'un art mexicain particulier ${ }^{98}$.

Nous soutenons l'hypothèse que Rivera a respecté une rhétorique sur le marxisme et Marx, en saisissant, plastiquement, pour traduire la lutte des classes, lutte muée en combat, ce qui relevait dans la Bible d'une vision du Combat entre le bien et le mal, à savoir, l'Apocalypse de St-Jean (et judéo-chrétien). Le thème ancien de l'Apocalypse avec la "grande Prostituée de Babylone » et "la bête monstrueuse ", tout comme le thème du serpent à plumes, continue à "jouer en basse continue " ou " en avenue secrète » mais entièrement transformé, réélaboré à l'aune d'une ère tirée par un avantgardisme prônant la modernité, urbaine, industrielle, une éducation pour tous, revendiquant un vivre ensemble sans aliénation ni exploitation, revendiquant un monde meilleur. L'Apocalypse signifie la Révélation. Elle traite de la souffrance des innocents. Les visions invitent à la prise de conscience que le monde est menacé par une catastrophe, et elles promettent également un avenir meilleur à l'humanité, au terme d'un combat. Elle se situe dans une perspective "de révolution" moins extérieure qu'intérieure, intégrant «le bien et le mal» par le développement d'une conscience plus élevée ${ }^{99}$.

Dans la fresque, la Révélation passe par l'analyse marxiste, Marx ayant décrypté le capitalisme, sa réussite mondiale et sa brutalité dans l'exploitation, il en est «un nouveau Messie " désignant une "nouvelle terre promise». A l'opposé d'une ville embrasée, en révolution, c'est un paysage urbain ordonné et en paix que désigne Marx, c'est en une autre ville et d'autres modalités du vivre ensemble que se condense «l'idéal» marxiste, un idéal de paix à construire. C'est aussi le profond souhait de Diego Rivera ${ }^{100}$. Celui-ci semble le signifier en un art autonome, non dénué de profondeur, dans un communisme «à lui ». Ne demeure-t-il un libre penseur ?101

\section{De la tour de verre à la mégapole}

\section{Le peintre, le sculpteur et l'architecte}

L'insertion de l'architecture et de la ville dans le support mural par Diego Rivera nous paraît d'autant plus importante à observer que lui-même se définit comme peintre, sculpteur et architecte. Selon lui, le peintre sculpteur doit construire comme un ingénieur et concevoir comme un architecte. 
Figure 21 - El pintor, el escultor y el arquitecto (Visión política del pueblo méxicano).1923 - 1928. Escalinata y segundo piso de la secretaría de Educación Pública-SEP. México, Diego Rivera

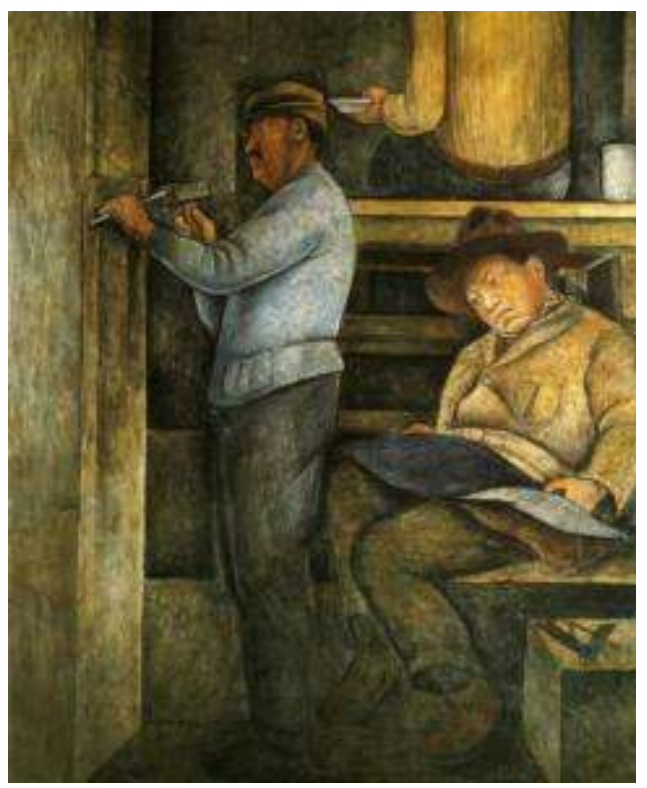

Il se peint lui-même en designer et constructeur de la ville industrielle aux USA ${ }^{102}$. En cela, il inscrit sa participation à un avant-gardisme propulsant un autre paradigme de la ville. Le Cubisme l'aide à produire cette rupture de temporalité. Pour Anna IndychLopez, l'innovation cubiste du mexicain s'affirme là : par les divers échafaudages dans les fresques ${ }^{103}$. "Mexico Today and Tomorrow includes a gridlike compartimentalization of space, created by a net work of pipe tubing. The cubism scaffold (...) $»^{104}$ Il n'est pas inutile de rappeler aussi que Rivera commanda à Juan O' Gorman une maison-atelier, composé de deux cubes et de verre, et relié ensemble par une passerelle. Il n'est pas non plus inutile de rappeler que ce geste intervint dans un contexte où le Mexique était resté imperméable à la modernité des années 1920, représentée par les architectes du Bauhaus ou de Le Corbusier.

Juan 0'Gorman fit partie de la jeune génération d'architectes radicaux, qui, les conditions socio-économiques et politiques aidant, va être le fer de lance d'une nouvelle architecture ${ }^{105}$. François Tomas, dans son ouvrage Les temporalités des villes, analyse l'essor au Mexique d'une architecture plus proche du Bauhaus que de Le Corbusier ${ }^{106}$.

Andréa Kettenmann a décrit la maison-atelier de Rivera ainsi « deux cubes dans le style du Bauhaus $»^{107}$. Et il s'avère que cette maison fait partie des premières réalisations « élevées suivant les principes du rationalisme moderne ${ }^{108}$. Il est certain qu'un style « radicalement nouveau » va faire flores, et, grâce aux nouveaux matériaux et à la possibilité de construire rapidement de grands ensembles à un moindre coût, il se diffuse sur le plan international. Ainsi, au Mexique, Narcisso Bassols, alors ministre de l'Education publique, opte pour le fonctionnalisme, dans un programme de construction scolaire ${ }^{109}$. Diego Rivera ${ }^{110}$ adopte le point de vue avant-gardiste, énergique et radical, en rupture avec les architectures traditionnelles de son pays et en faveur d'une modernité architecturale de style fonctionnel et international.

100 A la différence des miniatures du Moyen-âge, où la ville occidentale apparaît avec son architecture de pierre et dans un espace clos, fermé par les remparts, protégé par des 
fortifications, le bâtiment peint dans le mural gauche du Palacio Nacional, ressemble à une sorte de tour de verre transparente. Elle est formée par un échafaudage de tuyaux doublant ou enchevêtrant une infrastructure de béton ou éclectique. Elle est composée de quelques compartiments rectangulaires : cette structure faite de paliers en retraits successifs pourrait évoquer une ziggourat reposant sur une large terrasse. Ici la base est formée par l'Eglise, la caserne et un édifice caché, sans doute la prison, et les fondations sont ancrées par les agents de l'économie réelle. Prenant appui sur un monument baroque, la tour s'élève graduellement en édifice " de béton et de verre »: elle se donne à lire de manière étrange, paradoxale, à la fois "totalement ouverte ", « rigoureusement fermée » et cependant «fluide » par les réseaux tubulaires, les fils de téléphone, les flux d'informations, l'argent. Ainsi circulent les énergies.

L'architecture fonctionnaliste du style international s'accompagne de l'essor d'un complexe techno-économique financier international. A la différence encore des imageries de la fin du 19e et du début du 20e siècle en Europe, la tour de Diego ne présente pas une hiérarchie sociale, où le rez-de-chaussée est réservé aux concierges, le premier étage à la riche bourgeoisie, et, d'étage en étage, à une bourgeoisie mois riche puis à des familles ouvrières pour finir au dernier étage aux chambres de bonnes, aux étudiants ou aux artistes. La hiérarchisation que Diego nous donne à voir, est, par rapport à celle-ci, « renversée ».

Les pouvoirs hiérarchiques se donnent à lire dans un complexe pyramidal où le sommet est occupé par un autre modèle " économico-politique », avec la Bourse, Wall Street et l'élite financière des Etats-Unis, puis dans les niveaux inférieurs successifs, le gouvernement mexicain, ensuite le monde savant et industriel d'un côté, l'université de l'autre; les notables locaux, et enfin, l'Eglise. La ville n'est pas régie par les seuls pouvoirs locaux traditionnels. Elle est un amalgame de pouvoirs locaux, nationaux, cosmopolites, internationaux, reliés par des flux d'intérêts financiers et soudés les uns aux autres. Elle est une imbrication des espaces et des réseaux, formant un complexe technico-économique et financier international. C'est une mégapole dont l'empire s'étend sur un vaste territoire, aux limites incertaines et floues. Le peuple, les agents économiques, quant à eux, se trouvent non dans cette tour mais tout en bas dans les édifices semi-ouverts ${ }^{111}$ (l'Eglise, l'Ecole, la caserne, l'usine) ou dans des espaces ouverts (le champ, la place publique) et ils sont tous placés sous surveillance. Bien qu'ils participent à la construction de cette tour, ils ne maîtrisent pas les flux dont le système leur échappe. La Tour et son emprise sur les peuples offre une métaphore de l'empire capitaliste oppressif et de la lutte des classes.

Avec l'image de la Grande Prostituée de Babylone s'impose aussi la référence à Babylone la Grande: la force du mythe babélien et celle de l'Apocalypse nous entrainent à décrypter des couches de temporalités et d'imaginaire. A la Ville mégapole du vingtième siècle s'entremêle l'anachronisme de la Ville de Babylone: la tour qu'invente l'artiste Diego Rivera s'apparente à une Tour de Babel, emblème tragique de l'histoire et du destin d'une ville orgueilleuse, topos d'un palimpseste de villes gigantesques imprégnant considérablement l'imaginaire ${ }^{112}$.

\section{Le retour}

$\mathrm{Si}$, dans les différentes fresques de Diego Rivera, les valeurs traditionnelles de l'Empire aztèque sont ressaisies, si les valeurs de simplicité et d'humanisme s'y retrouvent, 
puisées, dans l'art de Giotto, les fresques de la Renaissance comme dans l'art populaire artisanal mexicain, Rivera opère un nouveau revirement après la seconde guerre mondiale, dans le modèle architectural. Vingt-cinq ans après la grande crise de 1929, et quinze ans après sa séparation du trotskisme, le communisme le plus internationaliste, Rivera renforce ses positions dites « nationalistes".

Ainsi, en juin 1954, Rivera a-t-il donné une importante conférence dans le Palacio de Bellas Artes: La huella de la historia y la geografia en la Arquitectura Mexicana, Primera Parte. Dans son exposé, il poursuit un double objectif: critiquer l'architecture de l'époque et aussi défendre son projet de Maison des Arts et des Artisans. Il affirme que l'expression mère, originaire de toutes les autres, c'est l'architecture; la grande architecture, la noble architecture, non pas la caisse de verre ou le caisson. Nous revenons donc à cette curieuse compartimentation, les caisses de verres pour les classes aisées ou les caissons destinés aux gens du peuple. Il oppose une architecture d'importateurs exportateurs, qui s'impose alors au Mexique de son époque, à une architecture traditionnelle, propre à une bourgeoisie progressiste capable de développer l'agriculture et consolider l'industrie, préoccupée par son peuple. Il critique un type de construction importé, déconnecté de l'économie réelle et un type d'habitat imposé. Pour lui, le paradigme type en est la Cité universitaire ${ }^{113}$. Combien de millions ont été nécessaires pour la construire, se demande Rivera, avec des matériaux importés, alors que l'on pouvait employer des produits existant dans la région. Les matériaux locaux, comme la terre et la pierre, utilisés dans l'architecture traditionnelle aztèque, ont été délaissés, et de plus, le paysage a été profondément bouleversé. En effet, il a fallu araser des collines, tout un paysage naturel.

La réaction de Rivera devient sarcastique, sur fond d'une analyse à la fois sociologique et artistique : que caray! Je me suis enrichi en important des caisses et en exportant des caisses. Des caisses, allez des caisses partout, même pour y habiter et si elles sont de cristal, et bah très bien !114 Ce modèle, promu dans " la ville idéale », ne déçoit-il désormais ? Son extension massive serait-elle dès lors vécue comme une brutalité voire une nouvelle forme de "colonisation»? Quelle est sa réponse, à lui, contre ce devenir homogénéisant, impersonnel, "générique » de l'architecture, dont il a pris conscience ? Ainsi Diego défendra son projet de la Casa de Anahuac, la maison des arts et des artisans, en s'inspirant des valeurs de l'architecture aztèque. Construite à nouveau avec l'architecte O'Gorman, elle constitue une " pyramide musée-mausolée ». 


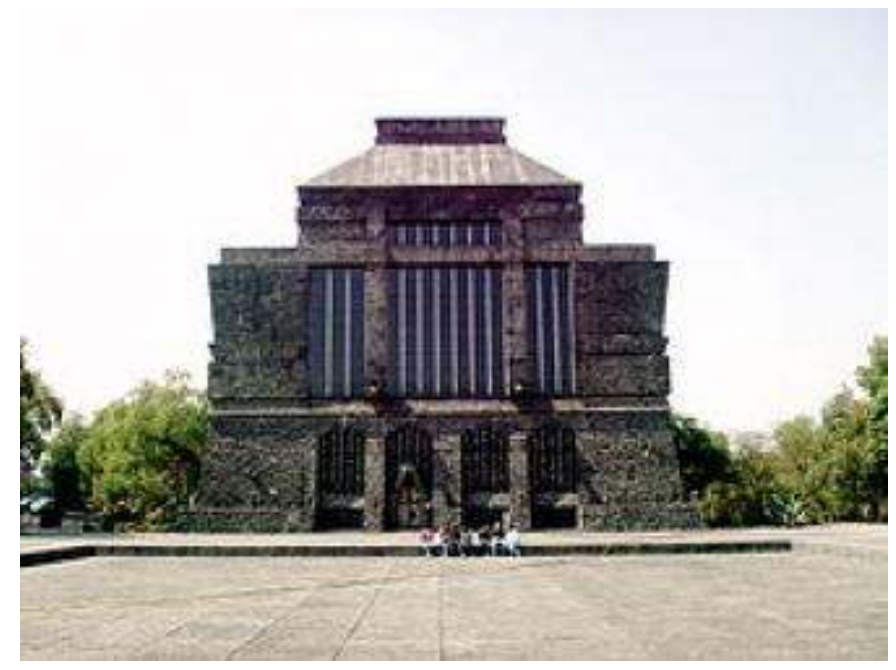

\section{Conclusion}

Cerner une fresque d'une telle ampleur est un défi. Tandis que les critiques se sont le plus souvent penchés sur les grands mouvements de l'œuvre, dans une histoire globale où les personnages en sont le sujet, notre approche a davantage voulu interroger le lien entre l'art et la technologie, partant, à l'inverse, d'un détail, le téléscripteur. L'analyse de ce «micro-objet» nous a conduits à l'observation d'un "macro-dispositif technologique». Il en émerge progressivement une mégapole moderne, dans un complexe technico-économique international, où Rivera questionne les modalités du "vivre ensemble ». Ce chemin d'exploration nous a réservé bien des surprises, mettant en cause l'idée d'un univers de l'art et la technologie "démythifié », et où des thèmes anciens, anachroniques, transformés, réélaborés, s'enchevêtrent et résistent à la contemporanéité, donnant à l'œuvre une profondeur et confortant sa dimension subversive.

La fresque se veut inscrire l'histoire: Le Mexique d'aujourd'hui et de demain. Le positionnement de Diego Rivera est intéressant car il se situe à des moments de césure, de révolutions et de changements de paradigme: plastique (cubisme, futurisme: dislocation des modèles et art mural); architectural (architecture avant-gardiste avec Le Corbusier et le Bauhaus, gratte-ciel); historique et politique (révolution au Mexique sur fond d'une histoire plus large, dans le temps et l'espace, de la lutte des classes); religieux (séparation de l'Eglise et de l'Etat); éducatif (volonté de développer l'éducation laïque); urbain (Mexique dit «en retard", par rapport à "un fonctionnalisme international») et enfin économique (réformes agraires, nouvelles technologies, industries, finances).

Rivera expérimente ce processus de transformation et ses croquis révèlent bien les tremblements de sa création. Le Serpent à plumes se mue en une armature technologique significative de l'ère industrielle et capitaliste. La civilisation mexicaine entre dans une nouvelle histoire. Il y a dissolution du temps et de l'espace par la technologie et la nouvelle hiérarchisation des pouvoirs. Mais le temps est aussi pensé de façon linéaire et cumulative, avec un commencement et tourné vers une fin ${ }^{115}$. Les mythes ressaisis par Rivera liés à la cosmogonie aztèque avec le Serpent à plume qui 
ressurgit en soleil aux langues de feu tout comme les récits de l'Apocalypse avec la cité idéale, demeurent des socles sur lesquels se sont édifiées des traditions de pensée. Toutes les formes de socialisme s'inscrivent dans cette lignée pour un Etat idéal ${ }^{116}$. Ces données se conjuguent chez Rivera pour formuler une "Révélation".

110 Historiquement, rappelle le philosophe athée Jacob Taubes ${ }^{117}$, les récits d'Apocalypse apparaissent pendant les périodes de persécution et parlent tous de renversement de l'ordre actuel du monde au profit d'un ordre supérieur: Ils surgissent dans les moments révolutionnaires et constituent la "véritable structure sous-jacente». Ainsi, précise-t-il, « il y a continuité entre l'eschatologie biblique et marxiste ». Les dialectiques y sont les mêmes : un monde insatisfaisant " croulant sous les contradictions ", un peuple ou une classe qui se manifeste, un événement qui vient briser l'histoire humaine, enfin l'établissement d'un ordre juste ${ }^{118}$. A cette fin, le mexicain produit un art tout aussi percutant que l'écriture de Marx lui-même. Dans son analyse du style de Marx, Alain Lhomme met en évidence "le feu d'artifice syntaxique, multipliant les inversions et le parallélisme, un jeu de rhétorique pour constituer un schème de pensée avec "cette figure du renversement $»^{119}$. De la même manière, Rivera n'offre-t-il un jeu similaire des parallélismes et de l'inversion, développant une rhétorique plastique binaire, triangulaire, une cascade de "croisées » au service d'une stratégie / pensée critique. Elle en forme le schème central. Ainsi l'avons-nous repéré dans notre analyse.

111 Le détail invisible, le téléscripteur, relève d'un programme action. Il est un pouvoir « invisible » et visible banalisé. L'argent ou l'or sont des fétiches pour Marx. Marx les compare au dieu universel abstrait du christianisme et dénonce ce fétichisme. - ce que reprend Diego sous forme de culte détourné au profit du dollar et du fascisme. Le saint du saint s'est déplacé. Entièrement intégré à la productivité du capital, travailleurs et populations sont soumis à ce "fétiche ", voire habités par lui : le téléscripteur s'insère dans les lieux de vie et engendre des fêtes. Téléscripteur et tubes forment un ensemble articulé. Il est nécessaire de qualifier ces tubes : réseau tubulaire, tubes énergétiques, tubes thermodynamiques faisant fonctionner la machine, échafaudage de la hiérarchisation des pouvoirs, réseaux urbains, infrastructure et superstructure tubulaire et urbaine, flux financiers, flux de l'information répressive, serpent, hydre ${ }^{120}$. Ils offrent une métaphore de l'ère industrielle, de l'empire capitaliste et aussi de la ville ${ }^{121}$. Cette technologie tubulaire renvoie à une architecture de compartiments « de béton et de verre ", qui s'inscrit dans un aménagement urbain et industriel, et qui, dans la peinture murale, préside également aux fondations de la Cité idéale. Ce courant avant-gardiste s'inscrit à une époque où sont en vigueur les principes de spécialisation du travail, la définition des fonctions au sein de la ville et les théories hygiénistes (la circulation de l'eau dans les maisons et la cité, l'exposition à la lumière, etc.). Un fonctionnalisme international gagne le Mexique. On ne peut dissocier la machine productiviste capitaliste de la ville : celle-ci en est sa projection sur le terrain ${ }^{122}$. Si Diego Rivera œuvre en faveur d'une modernité du Mexique, la peinture murale témoigne de la compréhension de ce qui fait système et de son engagement éducatif militant. Il nous présente une somme marxiste. Le politico religieux a longtemps dominé. Les Etats ont eu besoin de la religion pour légitimer leur pouvoir ; la religion participe à une cohésion sociale fondamentale. L'Etat a commencé à prendre ses distances, mais affronte la puissance des Etats-Unis et Wall Street. Malgré l'effort de l'Etat pour fonder une identité mexicaine singulière, cette puissance économique traverse les découpages politiques, s'attache des dépendances qu'elle articule à la Bourse et au marché. Le modèle urbain suit, et, un peu à la manière du Cubisme et du 
Futurisme disloquant un modèle et révolutionnant le regard, arrache à l'emprise des traditions, des codes et statuts établis ; cohabitent en facettes juxtaposées, en collages, à la fois séparés et soudés les uns aux autres, les " anciens " mondes et les «nouveaux " mondes en leurs vivants modèles au sein de la fresque. Si l'économie domine la société, la nation ethnique (ou les nations ethniques), puis la nation Etat (ou les nations Etats) du Mexique (mais aussi d'autres pays, ailleurs), ne sont-elles dépassées par « la nationmarché $»^{123}$ englobant l'aire de fabrication et de circulation des marchandises.

La théorie marxiste, tout comme le récit biblique, permettent de dénoncer la corruption et l'oppression des pouvoirs, et d'élever la conscience de sorte que ce système perverti s'effondre ou/et cède la place à un monde rénové, à construire sur des bases éthiques, avec des modalités du vivre ensemble différentes. Diego Rivera tient de multiples discours superposés et entremêlés, parmi lesquels :

a. Un discours politique s'adressant à l'individu social, soumis aux automatismes de son milieu, et où les communautés ou les nations doivent se prendre en main et se mobiliser en groupes de force dans un univers oppressif et répressif, lui-même organisé en champs de force.

b. Un discours sur les temporalités, les espaces et les imaginaires. Lieu mythique (Babylone), lieu de civilisations nouvelles (New-York, Mexico), la ville est une entité en elle-même, un sujet à part entière. Il est ici projection sur le terrain d'une machine productiviste capitaliste, broyante, et projection imaginaire d'une cité idéale, d'une autre "Cité de Dieu, parée comme une femme attendant son époux $»^{124}$, royaume de Dieu ou Société sans classe, déjà là.

c. Un discours sur le système de croyances et ses rites et rituels : croyances religieuses avec ses cultes, croyance en des systèmes sociopolitique et politico-économique, avec les nouvelles idoles (téléscripteur et Bourse) et ses rituels, croyance sinon espoir fondé sur un système laïc, une éducation et un nouvel humanisme.

d. Un discours sur le mauvais gouvernement et le bon gouvernement, ce dernier inspiré par les fresques de Lorenzetti et probablement de celles de Mantegna, au Palais ducal de Mantoue dans la célèbre Chambre des Epoux ${ }^{125}$.

Diego Rivera met en valeur "un monde insatisfaisant " en décryptant l'ensemble fonctionnel qui le construit. Il s'agit d'un système de flux fonctionnant comme une grande machine avec trois noyaux, pourrait-on avancer. Le noyau productif, avec au sommet de la tour de verre, les technologies financières et les responsables du système financier international, et à la base de la pyramide-ziggourat, les agents économiques. Le noyau répressif, pour contenir les tensions sociales générées par l'insensibilité des dirigeants vis-à-vis des conditions de vies humaines et par les crises fondées sur le capital fictif, entraînant les peuples dans la misère. Enfin, un noyau sémiotique, avec des images symboliques ou sacrées, qu'elles soient traditionnelles et profondes (la Vierge de Guadalupe) ou transgressives et séduisantes (la prostituée, la corruption, le culte du sexe) industrielles et scientifiques (les savants, l'université). Leur combinaison forme système. Cet ensemble techno-financier n'est pas isolé mais immergé dans le fourmillement social de la ville et du pays, transformant, dans le panorama de la fresque, les hommes "homme/nature » en «sujet/objet» et en hybride "homme/ machine ». Le formidable système de tubes désigne et relie les différents espaces signifiants: le jeu des "nœuds" «de cercles" et des "flèches" est la base d'une "systémique ». Les "noyaux durs" sont vecteurs d'homogénéisation et perpétuent, sous une autre forme, une sorte de colonisation. Les résistances, portées par les anciens mythes réactivés (Quetzalcoatl, Marx Moïse, Babel, les récits de l'Apocalypse) et par les 
marges (camarades et sœurs Kalho), se transforment en rébellion des paysans et des ouvriers, provoquant une révolution.

\section{D'hier à aujourd'hui. La perception lucide de Diego, visionnaire}

114 Rivera a eu une perception lucide du monde, en mettant au cœur du système un objet, le téléscripteur et un dispositif tubulaire porteur de ses flux, en ses ramifications discrètes, parfois presque invisibles, en hydre, pour déconstruire le fonctionnement du capitalisme financier. Et en en dénonçant sa traduction dans le domaine de l'architecture et de l'urbanisme, n'apparaît-il comme un visionnaire? La technologie a évolué, le téléscripteur s'est mu en ordinateur et robots, les appareils de surveillance en vidéo surveillance. Aujourd'hui, plus personne n'ignore à quel point l'ordinateur a joué et ne cesse de jouer un rôle clé, en accélérant sans cesse la vitesse de la transmission des informations avec précision, en permettant aussi de faire des projections de produits financiers virtuels, chaque fois plus sophistiqués mais aussi plus risqués. Lors de la dernière crise de 2008 , dont les effets se répercutent encore sur notre vie quotidienne, on a entendu même parler de cafards, sorte de robots traders qui fonctionnent de manière autonome et passent des ordres sans supervision humaine. Goldman Sachs, parmi d'autres, a fait de cette manière un bénéfice net de 2 milliards de dollars américains durant le premier trimestre 2009, donc tout juste après la crise ${ }^{126}$.

Ce dispositif de tubes porteurs des flux financiers, flux d'informations et de savoirs, flux d'images, a, avec le numérique, envahi notre monde d'aujourd'hui. Nous sommes pris, traversés par ces flux de toute sorte, l'intelligence artificielle circulant dans la vie quotidienne notamment par les ordinateurs, portables, télévision, reliés et combinés, et auxquels nous sommes branchés. Au début du XXe siècle, les travailleurs étaient confrontés à la matière. Ils vivaient une sorte de corps à corps avec la nature et avec la machine. D'hier à aujourd'hui, les populations ont leurs énergies happées par la machine. Ne sommes-nous désormais, nous, dans un corps à corps bizarre avec les univers dématérialisés, les intelligences immatérielles, dans un autre type d'artificialité. L'artiste mexicain fait apparaître d'un côté les maîtres des flux, de l'autre, la masse des flux-floués. Cette image s'imposerait-elle encore à notre humanité en ce début du XXIe siècle ? ${ }^{127}$.

116 Le local est devenu une sorte d'imbrication entre le local et le planétaire. En réaction à l'extension d'un fonctionnalisme international, à une artificialité d'un système de construction, brutal et homogénéisant, Diego Rivera, quelques années plus tard (dans les années cinquante) revient à l'architecture aztèque et promeut un modèle inscrit dans une chaîne de savoirs ancestraux et de savoir-faire artisanaux, tenant compte de sa culture. Cette singularisation peut-elle encore faire sens aujourd'hui? Pour faire société par tous, entre égaux et différents, nous dit Paul Blanquart, un autre type de systémique, non moins complexe mais différent, devrait être possible : "Que ce soit des lieux ou des gens, il s'agit de favoriser la singularisation. On est uni dans la mesure où l'on est distinct $»^{128}$. Ce qui entraîne une autre façon de faire territoire. 


\section{BIBLIOGRAPHIE}

ACEVEDO, Esther, et Universidad Iberoamericana (Mexico City, Mexico); Consejo Nacional de Fomento Educativo (Mexico). Guía de murales del Centro Histórico de la Ciudad de México. [Mexico]: Universidad Iberoamericana Departamento de Arte ;CONAFE, 1984

ANDRÉ-SALVINI, Béatrice, Philippe DUPONT, et Henri LOYRETTE, Musée du Louvre (Paris), RDA) Staatliche Museen (Berlin, et British museum (Londres). Babylone, 2008

APOLLINAIRE, Guillaume, Dorothea EIMERT, et Anatoli SAVIELEVITCH PODOKSIK. Le cubisme. Collection Art of century, 2010

ARAGON, Louis, Jean RISTAT, et Jacques LEENHARDT. Écrits sur l'art moderne, 2011

ARASSE, Daniel. Le détail : pour une histoire rapprochée de la peinture. Champs, ISSN 0151-8089 ; 624Champs. Art (Paris), ISSN 1248-7104, 2008

ARASSE, Daniel. On n'y voit rien : descriptions : essai, 2000

ARASSE, Daniel, Bernard Comment, et Catherine Bédard. Histoires de peintures. Folio. Essais, ISSN 0769-6418; 469, 2006

ARDEN QUIN, Carmelo (1913-), et Maison de l'Amérique latine (Paris). Face à la machine : Carmelo Arden Quin, Martha Boto, Marta Colvin .Maison de l'Amérique latine. Paris, 7 décembre 1984-11 janvier 1985, 1984

BARNITZ, Jacqueline. Twentieth-century art of Latin America. University of Texas Press, 2001

BASCHET, Jérôme. La rébellion zapatiste : insurrection indienne et résistance planétaire. Champs, ISSN 0151-8089; 589, 2005

BLANQUART, Paul. Une histoire de la ville : pour repenser la société. La Découverte-poche. Essais, ISSN $1272-1514 ; 59,2004$

BRUMFIEL, Elizabeth M, Gary M FEINMAN, et Field Museum of Natural History. The Aztec world, 2008

CARDENAL Ernesto, Presentando la poesía gringa, Casa de las Américas, $\mathrm{N}^{\circ} 250,2008$

CENTRE NATIONAL d'ART et de Culture GEORGES POMPIDOU (Paris). Le futurisme à Paris : une avant-garde explosive au Centre Pompidou : [exposition... Paris, Centre Pompidou, 15 octobre 2008-26 janvier 2009], 2008

COCKCROFT, James. Diego Rivera. New York : Chelsea House, 1991

COLLOQUE NATIONAL INTERDISCIPLINAIRE (1984; Caen), et Centre de recherche sur la modernité (Caen). L'Archaïsme ; acte du colloque national interdisciplinaire des 27 et 28 janvier 198, 1984

CRAVEN, David. Diego Rivera : as epic modernist. New York NY: G. K. Hall, 1997

DAIX, Pierre. Picasso créateur : la vie intime et l'œuvre. Paris : Seuil, 1987

Dictionnaire de l'art et des artistes, Fernand Nathan, 1982

DOUPHIS, Pierre-Olivier. « Diego Rivera. La révolution en chantant. », s. d. http://www.revuetextimage.com/01_e... 
FAURE, Élie. Histoire de l'art. , L'esprit des formes. Tome I. Le Livre de poche. Illustré. Série Art, ISSN 0294-1023, 1966

FERRIER, Jean-Louis, Yann LE PICHON, et Pontus HULTEN. L'aventure de l'art au XXe siècle, 2009.

GALINDO, Carmen. La ciudad de México : centro historico. 1er éd. México D.F. : Reproducciones Fotomecánicas, 1997

GOLDMANN, Annie. Essais sur les formes et leurs significations. Paris : Denoël/Gonthier, 1981

GRUZINSKI, Serge. Le destin brisé de l'empire aztèque. Découvertes Gallimard, ISSN 0988-0712 ; 33, 1987

HURLBURT, Laurance. The Mexican muralists in the United States. Albuquerque: University of New Mexico Press, 1991

JIMÉNEZ, Carlos. The Mexican American heritage. 2e éd. Berkeley Calif.: TQS Publications, 1994

KETTENMANN, Andrea. Diego Rivera, 1886-1957 : un esprit révolutionnaire dans l'art moderne. Traduit par Frédérique Daber, 2001

LACEY, Robert. Ford, the men and the machine. 1er éd. Boston: Little Brown, 1986

LAMBERT, Jean-Clarence. Le goût de Mexico. Le Goût des villes, ISSN 1636-919XLe Petit Mercure (Paris), ISSN 1269-8040, 2009

LAVAQUERIE-KLEIN, Christiane, et Laurence Paix-Rusterholtz. Les erreurs dans la peinture : sur une idée originale de Jean Poderos, 2011

LE MONDE Hors Série, Une vie une œuvre, N 10, Karl Marx - L'irréductible, décembre 2011

LOPEZ RANGEL, Rafael, et Enrique (1908-) Yáñez. Diego Rivera y la arquitectura mexicana, 1986

LOZANO, Luis-Martín. Diego Rivera, the complete murals. Hong Kong ;Los Angeles : Taschen, 2008

LOZANO, Luis-Martín, Juan Rafael Coronel Rivera, Benedikt Taschen, Rafael Doniz, et Francisco

Kochen. Diego Rivera : toutes les oeuvres murales, 2008

MARNHAM, Patrick. Diego Rivera : le rêveur éveillé : biographie. Traduit par André Roche. Fiction \& Cie, ISSN 0336-5344, 2000

MARNHAM, Patrick. Dreaming with his eyes open : a life of Diego Rivera. 1er éd. Berkeley [etc.]: University of California Press, 2000

MEADOWS MUSEUM (Dallas, Tex. ). Diego Rivera : the cubist portraits 1913-1917 : [exhibition organized by the Meadows Museum at Southern Methodist University (SMU), June 21 -September 20, 2009], 2009

QUISPEL, Gilles. Le livre secret de l'Apocalypse : le dernier livre de la Bible. Paris : Éditions Albin Michel, 1981

Revue Chronic'Art 75, L'Occident et l'Apocalypse, Numéro spécial apocalypse, 75, Janvier février 2012.

RIVERA, Diego. Diego Rivera : sus frescos en el Palacio Nacional de México, breve descripción de los detalles = brief explanation of the details, his murals in the National Palace of Mexico. México D.F : Editorial Fotocolor, 1957

RIVERA, Diego. La Huella de la historia y la geografía en la arquitectura mexicana, 1964.

RIVERA, Diego. Rivera : les fresques de Mexico. Paris : Atlas, 1984 
RIVERA, Diego. et Instituto Nacional de Bellas Artes (Mexico). Diego Rivera : catálogo general de obra mural y fotografía personal. 1er éd. [Mexico City Mexico] : SEP Dirección General de Publicaciones y Medios ;Instituto Nacional de Bellas Artes, 1988

RIVERA, Diego. et Mexico. Diego Rivera y los murales de la Secretaría de Educación Pública. 1er éd. [Mexico City] : Secretaría de Educación Pública, 2002

ROCHFORT, Desmond. The murals of Diego Rivera. 1er éd. London: South Bank Board in collaboration with Journeyman, 1987

SÁNCHEZ HERNÁNDEZ, Américo. Diego Rivera : los muros en papel, Consejo Nacional para la Cultura y las Artes, Instituto Nacional de Bellas Artes, Museo Mural Diego Rivera, 2003.

SCHMECKEBIER, Laurence. Modern Mexican art. Westport (Conn.): Greenwood press, 1971

SCHMOUKER Olivier. Les ordinateurs prennent le contrôle des Bourses :les affaires.com . 09-10-2009 (modifié le 30-09-2010 à 10 :51) http://www.lesaffaires.com/strategi...

SILVA E, R, et Mexico. Mexican history Diego Rivera's frescoes in the National Palace and elsewhere in Mexico City. A descriptive guide book of the National Palace and its royal rooms. New rev. and enl. ed. Mexico City: Sinalomex. Editorial, 1966

SILVA E., Roberto S. Mexican history : Diego Rivera's frescoes in the National Palace and elsewhere in Mexico City : A descriptive guide book of the National Palace and its royal rooms, 1966

SILVER, Kenneth E. Vers le retour à l'ordre : l'avant-garde parisienne et la première Guerre mondiale, 1914-1925. Traduit par Dennis Collins, 1991

SOUTER, Gerry. Diego Rivera. Traduit par Karin Py, 2009

SOUTER, Gerry. Diego Rivera : son art et ses passions. Collection Temporis, 2007

«Stock Ticker Company: The History of the Stock Ticker (Page 1)», s. d. http:// www.stocktickercompany.com/s...

TAUBES Jacob (1923-1987), Eschatologie occidentale, traduit de l'allemand par Raphael Lellouche et Michel Pennetier, Paris, Editions de l'Eclat, coll. « Philosophie imaginaire », 2009

TAUBES, Jacob, le Temps presse. Du culte à la culture. Paris, le Seuil, coll. «traces écrites », 2009.

TOMAS, François, et Jean-Noël Blanc. Les temporalités des villes, 2003

WISMANN, Heinz, et École des hautes études en sciences sociales (Paris). Walter Benjamin et Paris : colloque international, 27-29 juin 1983. Passages (Paris. 1986), ISSN 0298-9972 ;1, 1986

WOLFE, Bertram David. La vie fabuleuse de Diego Rivera : biographie. Traduit par Régine Cavallaro, 1994

WOLFE, Bertram David. The fabulous life of Diego Rivera. New York: Stein and Day, 1963

ZAKHEIM, Masha. Diego Rivera en San Francisco. 1er éd. Mexico D.F. : Consejo Nacional para la Cultura y las Artes ;Dirección General de Publicaciones, 1998

\section{NOTES}

1. Avec notamment: José Clemente Orozco, qui a retracé toute l'histoire du Mexique dans l'Hospicio Cabanas de Guadalajara; David Alfaro Siquieros, qui a peint «la Révolution mexicaine »; son compagnon de travail, Alva de la Canal ; le jeune français Jean Charlot avec « le 
massacre dans le temple majeur » dans l'escalier d'honneur de l'Ecole nationale préparatoire en 1922.

2. «On n'assiste pas à une ouverture aux idées nouvelles qui se propagent à travers l'Europe et une partie des Amériques. Ce qui s'est passé au Mexique ne ressemble en rien à ce qui prévalait au même moment ni dans la nouvelle URSS, ni en Argentine. (...) Il se produisit, en effet, par réaction, un rejet de tout ce qui pouvait en apparaître comme le prolongement ». (Tomas, F. \& Blanc, J.-N., 2003 :163)

3. Quelques éléments de la biographie : Après un apprentissage à l'Académie de San Carlos à Mexico, Rivera partit en Europe en 1907 et, après un séjour en Espagne, s'installa en France en 1909. Il s'exerça au cubisme de 1913 à 1917, fortement influencé par Picasso ; il fréquenta les peintres Matisse, Modigliani, Mondrian, le futuriste Severini, le poète Cocteau (en lien avec Diaghilev et les Ballets russes), le sculpteur Lipchitz et «le tout Montparnasse ». Il voyagea en Italie en 1920-1921, appréciant tout particulièrement les œuvres des artistes de la Renaissance italienne. A son retour au Mexique, sollicité par les autorités publiques, le peintre en 1921 élabore « la Création ». En 1928, il se rendit dans la nouvelle Union Soviétique et, entre 1930 et 1934, aux USA, où son séjour avec Frida Kalho pour la réalisation de fresques fut marqué par de violentes polémiques. Ces œuvres furent préservées, sauf l'une d'elles, détruite sur l'ordre du commanditaire John Rockefeller Junior. Si Diego fut farouchement hostile à l'Eglise et se déclarait athée, il adhéra cependant un long moment de sa vie à un ordre hermétiste ésotérique, celui des Rose Croix « Hermandad Rosacruz Quetzalcoatl» en lien avec la Franc-maçonnerie, au début de l'année 1920 ; un article édité par Taschen publie une photographie de lui dans la grande Loge en 1924 : c'est un aspect peu connu mais très important de sa vie. Après un nouveau séjour en Union soviétique pour des soins, il revint au Mexique et devant un parterre de journalistes, annonça qu'il était catholique. Ainsi l'empreinte d'une multitude de références peut-elle se retrouver dans son œuvre, unique et gigantesque.

4. (Tomas, F. \& Blanc, J.-N., $2003:$ p. 179)

5. (Arasse, D., 2000)

6. L'œuvre monumentale de Diego Rivera au sein du Palais évoque la Salle des Géants du Palais du Te à Mantoue, de la famille Gonzague, salle de la gigantomachie ou la guerre contre les géants, déclenchée par Zeus, avec l'homme exceptionnel, Héraclès. Mais Diego s'appuie également sur l'héritage précolombien et les techniques des fresques aztèques.

7. Expression reprise des Goncourt. (Arasse, D., 2006 : p. 284)

8. (Arasse, D., $2011: 10)$ - Longue Enquête d'Aby Warburg sur le serpent dans les traditions (voir aussi Didi Huberman).

9. "Une histoire du détail est impossible" affirme-t-il. (Arasse, D., $2008:$ p. 13)

10. Expression de Baudelaire. (Arasse, D., 2011 p. 29)

11. (Arasse, D., 2006 :p. 237)

12. (Meadows museum, 2009 :137-153)

13. (Meadows museum, 2009 :152-153)

14. (Faure,E. 1909 : p. 14)

15. (Faure, E, 1909 : 14)

16. (Stock Ticker Company, 2012)

17. (Lozano, Luis-Martín et al., 2008 : 29)

18. (Silva E, R. \& Mexico., 1966)

19. ] «... Un poco más a la derecha del profesor encontramos figuras célebres como Andrew Mellon, Vanderbilt, JP Morgan, William Durant Sinclair y Rockefeller, registrando las finanzas en una máquina ». (Rivera, D., $1957: 18$ )

20. «con quien Rivera acabara de tener un enfrentamiento con motivo del mural que pintara para el Rockefeller Center de Nueva York; Harry Sinclair, William Durant, JP Morgan. Cornelius Vanderbilt y finalmente Andrew Mellon »...(Acevedo, E. \& Universidad Iberoamericana : 121) 
21. "Junto al integrante de la dinastía bancaria estadounidense, Rivera colocó a Harry Sinclair, William Durant, JP Morgan, Cornelius Vanderbilt Andrew Mellon, personajes del mundo financiero de los Estados Unidos. » ...(Galindo, C., 1997: 28)

22. " And around watching the ticker tape of the stock market of NY we find very well known people, from right to left around the ticker tape are; Andrew Mellon, the ex-treasurer of United States, Cornelius Vanderbilt, a prominent railroad financier and philanthropist and also JP Morgan, whose nose is the only thing that can be seen behind the money pipe. The next in the center is William Durant, the former head of the GM of USA Harry Sinclair, and John D. Rockefeller Jr.". (Silva E, R. \& Mexico., 1966)

23. "US bourgeoisie (from left to right): Rockeff, Dinclaire, Durant, pierpont Morgan, Vanderbilt and Andrew Mellon ». (Lozano, Luis-Martín, 2008 : 229)

24. «John O. Rockefeller Ir.; Harry Sinclair; William Durant, antiguo director de la General Motors; JP Morgan; Cornelius Vanderbilt, financiero de los ferrocarriles norteamericanos y filántropo; y Andrew Mellon, ex-tesorero de los Estados ». (Rivera, D. \& Instituto Nacional de Bellas Artes : 134)

25. (Rivera, D., $1984: 43$ )

26. (Hurlburt, L., $1991: 76$ )

27. Il s'agit en fait de Andrew Mellon qui fut Secrétaire d'État au Trésor du 4 mars 1921 au 12 février 1932.

28. (Cardenal, 2008:17)

29. "In the Court of Fiestas, Rivera also celebrated Mexico's resources. The first floor is devoted to Mexican folklore ... he included JD Rockefeller, Henry Ford, and JP Morgan among the diners ». (Barnitz, J., 2001:12)

30. "These include sardonic scenes of John D. Rockefeller, Henry Ford, and JP Morgan in the Wall Street Banquet (2.05 x 1.55 meters), ». (Craven, D., 1997: 89)

31. «Amongst these assembled figures are recognisable caricatures of John D. Rockefeller, (on the top left of the table), JP Morgan and Henry Ford. In the panel called 'The Capitalist Dinner' Rivera continues his satire of the rich's ». (Rochfort, D., 1987: 33)

32. "... una foto de la escalera principal en la Torre de la Bolsa de Valores sobre la que se sobrepuso una réplica del fresco de Rivera Noche de los ricos - que ofrecía una visión satírica de Henry Ford, John P. Morgan y Nelson Rockefeller, ... ». ( Zakheim, M., 1998 : 15)

33. "JR Morgan Jr. Henry Ford y sus acompañantes beben champán junto a John D. Rockefeller al que Rivera en concesión a su edad - ochenta y ocho años a la fecha de ejecución de la pintura - proporcionó un nutritivo vaso de leche ». (Rivera, D. \& Mexico., 2002: 143)

34. "The illustrations shows Mexican and American capitalists and their womenfolk, at a table before champagne and ticker tape, a bank vault, loudspeakers, the ticker, and a replica of the Statue of Liberty. Those at table include caricatures of John D. Rockefeller the First, the elder JP Morgan, and Henry Ford. Certainly, when the Rockefeller hired Diego to decorate Radio City, they could not allege that they were not forewarned ». (Wolfe, B., 1963: 312)

35. "given in the ballad but was also used by Rivera on the first floor and is continued in a very free manner here. ... Rockefeller, Morgan, and Ford at a table with champagne, the Statue of Liberty, and ticker tape (Figure 164)". (Schmeckebier, L., 1971: 135)

36. "The seated plutocrats include John D. Rockefeller, Henry Ford and JP Morgan, two of whom were subsequently to ...In the panel entitled Wall Street Banquet Rivera showed millionaires poring over the stock-market ticker tape which snakes between their champagne glasses." (Marnham, P., 2000b: 205)

37. "He painted the controversial Wall Street banquet panel, showing the billionaires John D. Rockefeller, Sr., JP Morgan, and Henry Ford dining on ticker tape. He also designed the sets and costumes for a Carlos Chavez ballet..." (Cockcroft, J., 1991: 73)

38. «Diego Rivera: Continued. a revolutionary idea which questioned all of the existing art forms. ... and he included in this mural series the 'Capitalists Banquet' which parodied Henry Ford, JP Morgan and John David Rockefeller as they sit at the dinner table while reading the stock market's ticket tape ». (Jiménez, C., 1994: 145) 
39. "In 1930 the name of Diego Rivera was already well known on the Euro-American art circuit. ... Capitalist Dinner, showed John D. Rockefeller, JP Morgan, and Henry Ford, all gathered around a table, dining on ticker tape..." (Lacey, R., $1986: 317)$

40. (Goldmann, A., 1981 : p. 199)

41. Lowy mentionne, partant d'une description à partir du sommet, énonce qu'ils aboutissent devant l'autel de la Vierge de Guadalupe et signale entre parenthèses «l'un d'eux prend même racine directement dans l'image sainte ». (Goldmann, A.1981: 199).

42. (Brumfiel, E., 2008 : p. 218-219)

43. Le Vert, le signe de l'espérance; le blanc, celui de la paix; le rouge, le sang des patriotes. (Musset, A., $1996:$ 40)

44. Lowy : «Pour qu'on ne se trompe pas sur leur signification, Rivera les a placés sous le double signe du fascisme et du dollar, et les a liés tous directement à l'appareil qui représente la Bourse de New York ». (Goldmann, A., $1981: 199)$

45. (Daix, P., 1987 : 31)

46. Bien que Picasso s'en défende.

47. (Grandclaudon, C. $2006:$ p 109-129). "Musées, ethnographie, territoires, 1800-1998 » in Barbe, Noël, (sous la direction de). Culture et territoires, qualifications culturelles et inscriptions territoriales, CRDP Franche-Comté, 2006.

48. Au 19e siècle, les recherches scientifiques en anthropologie représentent un enjeu crucial à une époque marquée par des conceptions anti égalitaires des races, le culte de caractères nationaux puis le mythe du surhomme. Les débats sur les identités et les races perdurent au début du 20e siècle et s'exacerbent plus tard sous le régime nazi. Les idéologies de la décadence et de la dégénérescence et les théories de l'eugénisme se développaient greffées sur l'inquiétude liée à l'exode rural, à la fin du 19e siècle, et l'essor des villes et de l'industrialisation, surtout Paris, où se développe un cosmopolitisme. Par ailleurs, il ne fut pas un seul champ de la connaissance qui ne reçut le choc des travaux de Darwin. (Grandclaudon, 2006, in Barbe, N.)

49. Le texte fondateur du cubisme est posé par Guyaume Apollinaire «Les peintres cubistes, méditations esthétiques ». (Apollinaire, G. ; Eimert, D., 2010 : p. 7-26)

50. « Nous voulons chanter l'amour du danger, l'habitude de l'énergie et de la témérité ». " Nous voulons exalter le mouvement agressif (..), la gifle et le coup de poing ». " Nous déclarons que la splendeur du monde s'est enrichie d'une beauté nouvelle : la beauté de la vitesse. Une automobile de course avec son coffre orné de gros tuyaux tels des serpents à l'haleine explosive (...). « Nous voulons chanter l'homme qui tient le volant, dont la tige idéale traverse la terre, lancée ellemême sur le circuit de son orbite ». Extrait du manifeste du Futurisme, signé par Filippo Tommaso Marinetti, paru dans le Figaro du 20 février 1909.

51. (Wolfe, B., 1994: p. 90)

52. (Kettenmann, A., 2001: p. 91)

53. François Charcot peint le mural «Le massacre dans le Temple Majeur ", à Mexico en 1922, procédant de l'art mural précolombien, des recherches d'artistes modernes tels que Matisse et Léger et des Fresques de la Renaissance. (Ferrier, J.L., 2009 : 223)

54. Diego Rivera travaillera sur la base d'une importante documentation photographique réunie par les enquêtes de terrain d'anthropologues, et notamment par son ami Manuel Gamio, directeur de l'anthropologie et des fouilles archéologiques de Teotihuacan. (Rivera, C., 2008: p. 29)

55. (Wolfe, B.D., 1994: p. 91)

56. (Wolfe, B.D., 1994: p. 91)

57. Citons notamment ces ouvrages: (Silver, K. E., 1992); (Centre interdisciplinaire d'Etudes et de Recherche sur l'expression contemporaine, 1980 et 1986). Kenneth E. Silver, Vers le retour à l'ordre, l'avant-garde parisienne et la 1re guerre mondiale, Ed. Flammarion, 1992. Centre interdisciplinaire d'Etudes et de Recherche sur l'expression contemporaine. L'art face à la crise, l'art en Occident, 1929-1939, Université de Saint-Etienne, 1980 et Le Retour à l'ordre dans les arts plastiques et 
l'architecture, 1919-1925, Université de Saint-Etienne, 1986. Seul le surréalisme se tient à l'écart et se développera aux USA.

58. (Wolfe, B.D., 1994)

59. Trotski « accuse d'idéalisme les tenants de l'avant-garde »; Lénine éprouve " des réticences vis-à-vis de l'art moderne ». La censure est établie vis-à-vis de tous les mouvements d'avantgarde (futurisme, cubisme, suprématisme, constructivisme - bien que le cubisme et le futurisme furent des mouvements révolutionnaires en art et en partie prenante dans les mouvements sociaux. (Ferrier, J.L., 2009 : p. 225)

60. (Douphis, P.O.: p. 4) Cette même idée est développée dans (Souter, G. $2007:$ p. 157 et 160).

61. Lettre du 20 janvier 1933. (Wolfe, B., 1994 : p. 228-229)

62. The Detroit Institute of Arts, Detroit. Diego représente dans les fresques de Détroit également «la vaccination»; et en 1943-1944, il peint l'histoire de la cardiologie. Universidad Iberoamericana, auditorium Tiapan.

63. Museo del Palacio de Bellas Artes, Mexico.

64. 'La poésie de la machine, qu'on sentait naître dans les fresques de San Francisco, et même de Mexico, envahit celles de Détroit. Perforeuses d'où sort le feu, couronne rayonnante et crépitante des moteurs, rythme silencieux et dansant des pistons et des bielles battant la cadence d'une marche nouvelle à quoi s'essaie l'humanité encore titubante, féerie des usines, des gares, des chantiers, des arches illuminées sur l'océan, des tours babyloniennes sur les villes, torches, phares, fournaises du monde bouleversé qui flamboient dans la nuit et renvoient au ciel les éclairs qu'ils lui ont arrachés, vous faites désormais partie de notre vie intérieure, et malheur à qui ne le sent pas. La haine qu'on vous manifeste, c'est de l'amour. L'homme éprouve de nouveau le besoin de s'entendre avec l'homme au sein des forces mêmes et par les forces mêmes qu'il a déchaînées pour les reprendre et les réenchaîner. Nouveaux 'sujets' - nouveaux motifs, nouveaux prétextes d'émotion. [...] Le Mexique peut être fier de posséder des ouvriers de la peinture qui les sentent approcher.' (Extrait d'un article Publié dans Art et Médecine) - Elle Faure, 'La peinture mexicaine', Art et Médecine, avril 1934.

65. (Souter, G., $2007: p$ 195-196)

66. (Souter, G. 2007 : p. 220)

67. Guerre Cristera en 1926. Dans cette période de troubles, Diego Rivera conduit un mouvement d'agitation sociale, avec des paysans formés par l'Eglise elle-même, qu'il retourne contre celle-ci : Un document « manifeste » est publié portant le titre « La répartition des terres entre les pauvres n'est pas contraire aux Enseignements de notre Seigneur Jésus-Christ de notre Sainte Mère l'Eglise ». Le dessin de Diego Rivera représente un Sacré-Cœur, symbole du catholicisme social. (Rivera,C., $2008:$ p. 29)

68. (Lavaquerie-Klein, C. ; Paix-Rusterholz, L., 2011).

69. (Arrasse, D. $2006:$ p. 73-85)

70. (Aragon, L. 1926: p. 144-145). "Les signes extérieurs d'un culte, la représentation figurée de ses divinités avant tout m'importent, et je laisse aux habiles leurs interprétations de finesse des plus belles histoires auxquelles l'homme ait su mêler le ciel. Je traverserai ces champs énormes semés d'astres. Si je parcours les campagnes, je ne vois que des oratoires déserts, des calvaires renversés. Le cheminement humain a délaissé ces stations, qui exigeaient un tout autre train que celui qu'il mène. Ces Vierges, les plis dans leur robe supposaient un procès de la réflexion point compatible avec le principe d'accélération qui gouverne aujourd'hui le passage. (...) Devant qui s'arrêtera-t-elle donc, la pensée contemporaine, le long de ces routes où des dangers nouveaux qui l'alimentent, devant qui humiliera-t-elle la vitesse acquise et le sentiment de la fatalité ? Ce sont de grands dieux rouges, de grands dieux jaunes, de grands dieux verts, fichés sur le bord des pistes spéculatives que l'esprit emprunte d'un sentiment à l'autre, d'une idée à sa conséquence dans sa course à l'accomplissement. Un étrange statuaire préside à la naissance de ces simulacres. (...) Les sculpteurs sans nom qui ont élevé ces fantômes métalliques ignoraient se plier à une tradition aussi vive que celle qui traçait les églises en croix. Ces idoles ont entre elles une parenté qui les rend redoutables. Bariolés de mots anglais et de mots de création nouvelle, avec un seul bras long et souple, 
une tête lumineuse sans visage, le pied unique et le ventre à la roue chiffrée, les distributeurs d'essence ont parfois l'allure des divinités d'Egypte ou de celles des peuplades anthropophages qui n'adorent que la guerre. O Texaco motor oil, Eco, Shell, grandes inscriptions du potentiel humain! Bientôt nous nous signerons devant vos fontaines, et les plus jeunes d'entre nous périront d'avoir considéré leurs nymphes dans le naphte.». Le Paysan de Paris.Voir également: Louis Aragon, Ecrits sur l'art moderne. (Préface Leenhardt, J., 2011)

71. Fresque de Détroit. The Detroit Institute of Arts. L'industrie de Détroit (mur nord). Usine de bombes au gaz toxique et Cellules se détruisant sous l'effet du gaz. 1932-1933.

72. (Quispel, G., 1981: p.94). L'image présente des correspondances avec le fragment de Diego Rivera.

73. Carranza fit adopter la constitution en 1917, et préconise une politique socialisante. Suite à son assassinat, par un catholique, une violente résistance catholique déclenche, à l'époque de Calles (1924-1928) une politique anticléricale extrêmement dure. La période qui suit, avec Cardenas, est marquée par une politique d'indépendance économique et de modernisation, avec le souci d'apaiser les luttes religieuses.

74. Idem

75. Cuvre qui prit le titre des « Demoiselles d'Avignon ».

76. La première exposition de Orozco eu lieu à Mexico en 1915. Elle comprend 123 œuvres sur la vie des prostituées. Dans la courte mention du Dictionnaire de l'art et des artistes, 1/3 du texte est consacré à celle-ci. (Fernand Hazan, $1982:$ p. 435)

77. Dans un contexte aussi où la laïcité s'est accompagnée de la rupture d'une chaîne de repères de la culture chrétienne et, peut-être aussi, de l'absence de curiosité voire de rejets vis-à-vis de grands textes sacrés, dans une confusion entre croyance et culture. (Jacob Taubes, J., 2009)

78. le Livre Secret de l'Apocalypse. Voir les célèbres tapisseries d'Angers du 14e siècle; les peintures néerlandaises; les manuscrits de la Bibliothèque nationale de France, l'Apocalypse de Trève, d'Oxford, l'œuvre de Dürer, le monastère royal de l'Escurial, la cathédrale de Burgo de Osma, le trésor de la Cathédrale de Gérone, le polyptique des Van Eyck pour l'autel de la cathédrale de Gand, les Apocalypse de Bourges, Peterborough, Douce, Memling, San Angelo in Formis, Valenciennes, Seo de Burgel, Estence, etc. avec de multiples variantes. (Quispel, G., 1981)

79. (Quispel, G., $1981:$ p. 164)

80. (Quispel, G., 1981 : p. 164)

81. Leurs lèvres ne se touchent en fait pas.

82. (Quispel, G., 1981 : p. 96)

83. (Quispel, G., $1981:$ p. 94)

84. (Quispel, G., 1981 : 94)

85. Les sept rois désignent les sept empereurs de l'Empire romain, mais le chiffre sept peut être affecté d'un sens symbolique et non arithmétique. (Quispel, G., 1981 :97)

86. Lors de la guerre d'indépendance en 1810 contre le pouvoir espagnol, la vierge de Guadalupe est la patronne de l'armée des insurgés, et la Vierge est aussi l'emblème du parti royaliste. Jacques Lafaye, 2002. (Brumfiel, E., 2008 : p. 218)

87. Le révérend Mr Higgins de l'Eglise épiscopale de la Woodward Avenue 'Si le génie de notre peuple est pur matérialisme et athéisme, si nos Dieux sont la Science et le Sexe, si la brutalité de l'âge industriel est la seule vertu que notre belle cité exprime, si ces choses sont justes, alors M. Rivera doit être salué comme le Michel-Ange moderne. Bien sûr, ne sont-ils pas assez nombreux dans notre population à n'avoir pas plié le genou devant Baal pour justifier de l'inclusion dans le mural d'au moins une petite suggestion d'intuition et d'aspiration spirituelles ?'- Mgr Doyie» l'œuvre est un affront pour des millions de catholiques». (Wolfe, B. 1994 : p. 228)

88. (Kettenmann, A., $2001:$ p. 91)

89. (Goldmann, A. $1981:$ p. 207) 
90. Discours de Jean Jaurès, journaliste et homme politique, fondateur de l'Humanité, codirecteur de la section française de l'Internationale ouvrière avec le marxiste Jules Guesde. Karl Marx et Friedrich Engels ont publié « Ecrits sur la religion ». (Le Monde , 2011 : 69)

91. (Le Monde , $2011: 69$ )

92. (Rivera, C., 2008 : p. 28-29)

93. «Grace aux fresques des peintres italiens, depuis les Byzantins jusqu'à Michel-Ange, il avait trouvé la réponse aux exigences d'un art populaire qui fut en mesure de nourrir esthétiquement les masses, de corriger leur goût, de leur raconter une histoire aussi émouvante que celle des églises médiévales (...) ». (Wolfe, B.D., 1994: p. 91)

94. (Douphis, P-0.: p. 1-12)

95. (Douphis,P-O.::p. 5)

96. (Patrick Narmham, p. 230) Diego Rivera, le Rêveur éveillé, Paris, Seuil, p. 230. Analyse également de Pierre-Oliver Douphis.

97. «Au regard d'une disjonction entre le bien et le mal posée de manière aussi didactique, il (Diego) prit peut-être en considération les méthodes d'évangélisation des indigènes employées par les missionnaires depuis le 16e siècle ». (Lozano, L.M., $2008:$ p. 138)

98. (Douphis, P-O.: p. 8)

99. (Quispel, G., 1981: p.129). Cette approche est en correspondance avec les préceptes philosophiques rose-croix (Rivera, C., 2008 : p. 28-29) et (Lozano, L.M., 2008 : p. 137-139)

100. Au-delà de l'idéologie marxiste reconnue, Lozano se réfère directement au souci de Diego Rivera : "Rivera préconise la direction d'un bon gouvernement qui permettrait la stabilité et le progrès: les infrastructures du pays et les populations vivraient dans la paix et l'harmonie ». Il précise aussi : "Nous savons que son idéologie fut en même temps nourrie d'une tradition hermétique lors de son passage par la Confrérie rose croix et très probablement en tant que franc-maçon ». (Luiz Martin Lozano, 2008: p. 139-140)

101. Lozano remarque que si Diego Rivera fut un communiste « pur et dur » et que son idéologie tout comme son crédo artistique visaient l'instauration d'une société plus équitable notamment envers les ouvriers et les paysans, sur toutes les causes, il resta cependant un libre-penseur. «Il est difficile de cataloguer ses peintures murales comme l'illustration d'une doctrine spécifique ». (Luiz Martin Lozano, 2008: p. 140)

102. Fresque The Making of a Fresco, showing the building of a City 1931, for the California School of Fine Arts. Les aspects pierre-compas-équerre sont les éléments habituels de l'attirail francmaçonnique. Les rose-croix du XXe siècle avaient d'importantes affinités avec la francmaçonnerie dont ils partageaient une partie des codes. (Rivera, C. , 2008: p. 30)

103. "An abstract Courbet »: The Cubist spaces of Rivera's murals". (Meadows Museum, Indych-Lopez, A., 2009: p. 152-153)

104. "An abstract Courbet »: The Cubist spaces of Rivera's murals". (Meadows Museum, Indych-Lopez, A., 2009 : p. 152-153)

105. Sous l'impulsion de José Villegran, qui s'imposera comme le maître incontesté de l'architecture mexicaine. Cette radicalisation a connu son apogée en 1938 avec la création de l'Union des Architectes socialistes et la nomination de Hannes MEYER, ex-directeur du Bauhaus, à la tête de l'Institut Polytechnique National où il contribua avec les architectes à la création d'une Ecole supérieure de Développement et d'Urbanisme. (François Thomas, $2003: p$ 183)

106. François Thomas, $2003: p$ 182)

107. (Kettenmann, A. 2001 : p 57). La première construction des architectes du Bauhaus, en 1926, utilise le béton armé et le verre, et cet édifice constituera l'une des œuvres majeures de l'architecture européenne des années vingt. (Dictionnaire de l'art et des artistes, $1982:$ p. 46)

108. (François Thomas, $2003: p$ 179)

109. «À la fois par conviction et pour construire plus d'établissements avec le même budget ». (François Thomas, $2003:$ p. 182) 
110. Bien qu'affecté par des incidents (exclusion du parti communiste mexicain et rupture du contrat avec le Rockfeller Center aux USA).

111. « difices semi-ouverts». (Lowy : $p$ 207)

112. L'imaginaire babélien s'étend au 20e siècle (et aussi au 21e siècle). New York n'y échappe pas. (Catalogue d'exposition Babylone, Musée du Louvre, 2008 : p. 437)

113. (López Rangel,1986:86)

114. (López Rangel,1986:86)

115. (Chronic'Art 75, Pierre Jouan, $2012:$ p. 51)

116. (Quispel, G. 1981 : p. 122)

117. Chronic'Art 75, Pierre Jouan, 2012 : p. 51)

118. Pour Jacob Taubes (1923-1987), l'Apocalypse n'est pas seulement un moment biblique, mais «le socle sur lequel s'était édifiée la tradition de pensée occidentale ». (Taubes, J., 2009)

119. (Le Monde, Alain Lhomme, 2012 : p. 95)

120. Nous souscrivons à l'interprétation d'Anna Indych-Lopez mentionnant que cet échafaudage et ces tubes relèvent artistiquement du Cubisme.

121. A Paris, le Centre Beaubourg Georges Pompidou et ses gros tuyaux, sera l'architecture emblématique du XXe siècle et de l'ère industrielle, installée en plein cœur de Paris en ses quartiers médiévaux et haussmanniens, ville musée en elle-même (1972 et ouvert au public en 1977, conçu par Renzo Piano et Richard Rogers).

122. Paul Blanquart développe sur un plan plus large historiquement, les correspondances entre les figures spatiales, les structures sociales et les formes mentales qui fondent la ville et témoignent d'une façon, en un temps et un lieu, d'être humain. (Blanquart, P., 2004)

123. (Blanquart, P., $1998:$ p. 137)

124. (Quispel, G. $1981:$ p. 112-113)

125. (Lozano, J.L., $2008:$ p. 136-143) ; (Arasse, D., $2011:$ p. 177-188)

126. (Schmouker, 2010)

127. C'est ce que dénonce avec vigueur le sociologue et philosophe Paul Blanquart. Le système de flux formate, modélise, la société voire la « zombifie » «Il y a un système qui est entubant. Mais est-ce que nous pouvons concevoir une autre systémique?». (Blanquart, P. Vidéo Les hussards de la formation 2009)

128. Cela veut aussi signifier qu'être citoyen de quelque part suppose donc qu'on est en même temps citoyen du monde et inversement. Ce citoyen est appelé à se singulariser en jouant un jeu, non pas formaté, mais un jeu particulier des circulations permises par le champ planétaire. "C'est vertigineux », conclue-t-il, "mais toutes les histoires de développement durable sont à la clé ». Et cette nouvelle façon entraîne aussi une nouvelle façon d'éduquer: de faire germer en chacun le potentiel original qui lui permettra d'acquérir sa forme et sa forme intéressante pour les autres. (Blanquart, P. Vidéo Les hussards de la formation 2009)

\section{RÉSUMÉS}

C'est entre 1929 et 1935 que Diego Rivera entreprend la réalisation de fresques au Palacio Nacional de Mexico. Nous abordons ici « le Mexique d'aujourd'hui et de demain ». Interrogeant le lien entre l'art et la technologie, notre approche s'est centrée sur un détail negligé par la critique, le téléscripteur. L'analyse de ce «micro-objet» nous a conduits à l'observation d'un 
«macro-dispositif technologique ». Il en émerge progressivement une mégapole moderne, dans un complexe technico-économique international, où Diego Rivera questionne les modalités du " vivre ensemble ». Ce chemin d'exploration nous a amenés à mettre en cause l'idée d'un univers de l'art et la technologie "démythifié ». S'y enchevêtrent des thèmes anciens et anachroniques confortant l'œuvre dans sa dimension subversive.

Entre 1929 y 1935 Diego Rivera pinta los murales del Palacio Nacional. Estos representan el compendio histórico más importante pintado en el siglo XX. Aquí analizamos el "México de hoy y de mañana", que forma parte del ciclo de frescos "Epopeya del pueblo mexicano". Mientras que los críticos analizan preferentemente los grandes personajes de esta obra o las sensibilidades políticas que se reflejan en ella, nuestro enfoque trata en primer lugar, de examinar la relación entre arte y tecnología, y en segundo lugar, de trabajar la historia de un detalle, un fragmento paradójicamente muy poco estudiado por la critica, aunque muy visible. El análisis de este "objeto invisible", ha conducido inexorablemente a la observación de una "macro-tecnológica del dispositivo." Poco a poco surge la visión de una metrópolis moderna, de un complejo sistema técnico-económico con sus ritos. Esta vía de exploración nos ofrece grandes sorpresas y la idea de un mundo artístico y tecnológico "desmitificado", donde viejos temas, transformados, reelaborados, resisten a la maraña de lo contemporáneo, dando a la obra una profundidad de dimensión subversiva.

\section{INDEX}

Mots-clés : architecture, art mural, détail, flux, apocalypse, Marx (Karl), mythologie, serpent à plume, technologie, téléscripteur, ville 